\title{
CONF-9405223--2
}

$\ldots$

\section{CHARPY IMPACT TEST RESULTS ON FIVE MATERIALS AND NIST VERIFICATION SPECIMENS USING INSTRUMENTED 2-mm AND 8-mm STRIKERS*}

\author{
Randy K. Nanstad and Mikhail A. Sokolov \\ Metals and Ceramics Division \\ OAK RIDGE NATIONAL LABORATORY \\ P.O. Box 2008 \\ Oak Ridge, TN 37831-6151
}

\begin{abstract}
*Research sponsored by the Office of Nuclear Regulatory Research, U.S. Nuclear Regulatory Commission, under Interagency Agreement DOE-1886-8109-8L with the U.S. Department of Energy under contract DE-AC05-84OR21400 with Martin Marietta Energy Systems, Inc.
\end{abstract}

\begin{abstract}
The submited manuscript has been authored by a contractor of the U.S. Government under contract No. DE-ACO5-84OP21400. Accordingty, the U.S. Government retains a nonexclusive, royaly-free ticense to publish or reproduce the

published form of this contribution, or allow others to do so, for U.S. Government purposes.
\end{abstract}

DISCLAIMER

This report was prepared as an account of work sponsored by an agency of the United States Government. Neither the United States Government nor any agency thereof, nor any of their employees, makes any warranty, express or implied, or assumes any legal liability or responsibility for the accuracy, completeness, or usefulness of any information, apparatus, product, or process disclosed, or represents that its use would not infringe privately owned rights. Reference herein to any specific commercial product, process, or service by trade name, trademark, manufacturer, or otherwise does not necessarily constitute or imply its endorsement, recommendation, or favoring by the United States Government or any agency thereof. The views and opinions of authors expressed herein do not necessarily state or reflect those of the United States Government or any agency thereof.

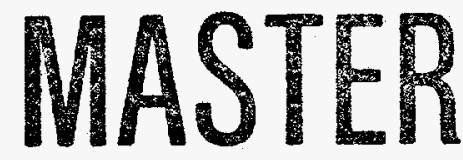




\section{DISCLAIMER}

Portions of this document may be illegible in electronic image products. Images are produced from the best available original document. 
Randy K. Nanstad' and Mikhail A. Sokolov'

\section{CHARPY IMPACT TEST RESULTS ON FIVE MATERIALS AND NIST VERIFICATION SPECIMENS USING INSTRUMENTED 2-mm AND 8-mm STRIKERS}

REFERENCE: Nanstad, R. K., and Sokolov, M. A., "Charpy Impact Test Results on Five Materials and NIST Verification Specimens Using Instrumented 2-mm and 8-mm Strikers," Pendulum Impact Machines: Procedures and Specimens for Verification, ASTM STP 1248, Thomas A. Siewert and A. Karl Schmieder, Eds., American Society for Testing and Materials, Philadelphia, 1995.

ABSTRACT: The Heavy-Section Steel Irradiation Program at Oak Ridge National Laboratory is involved in two cooperative projects, with international participants, both of which involve Charpy V-notch impact tests with instrumented strikers of 2-mm and 8-mm radii. Two heats of A 533 grade B class 1 pressure vessel steel and a low upper-shelf (LUS) submerged-arc (SA) weld were tested on the same Charpy machine, while one heat of a Russian $\mathrm{Cr}-\mathrm{Mo}-\mathrm{V}$ forging steel and a high upper-shelf (HUS) SA weld were tested on two different machines. The number of replicate tests at any one temperature ranged from 2 to 46 specimens. Prior to testing with each striker, verification specimens at the low, high, and super high energy levels from the National Institute of Standards and Technology (NIST) were tested. In the two series of verification tests, the tests with the $2-\mathrm{mm}$ striker met the requirements at the low and high energy levels but not at the super high energy. For one plate, the 2-mm striker showed somewhat higher average absorbed energies than those for the 8-mm striker at all three test temperatures. For the second plate and the LUS weld, however, the 2-mm striker showed somewhat lower energies at both test temperatures. For the Russian forging steel and the HUS weld, tests were conducted over a range of temperatures with tests at one laboratory using the 8-mm striker and tests at a second laboratory using the 2-mm striker. Lateral expansion was also measured for all specimens and the results are compared with the absorbed energy results. The overall results showed generally good agreement (within one standard deviation) in energy measurements by the two strikers. Load-time traces from the instrumented strikers were also compared and used to estimate shear fracture percentage. Four different formulas from the European Structural Integrity Society draft standard for instrumented Charpy test are compared and a new formula is proposed for estimation of percent shear from the force-time trace.

${ }^{1}$ Metals and Ceramics Division, Oak Ridge
P.O. Box 2008, Oak Ridge, TN 37831-6151.


KEYWORDS: Charpy impact testing, verification, 2-mm striker, 8-mm striker, lateral expansion, instrümented striker, energy, percent shear, standard deviation, plate, weld, forging

Charpy V-notch (CVN) impact testing is performed by hundreds of organizations around the world using very similar procedures, usually either that of the American Society for Testing and Materials (ASTM) [1] or that of the International Organization for Standardization (ISO) [2]. Unfortunately, two different specimen striker designs are described and are sufficiently different so that the equivalence of the test results is questionable. Figure 1 shows that the 2-mm striker described in the ISO standard is thinner and has a 2-mm radius compared to the 8-mm radius of the striker described in the ASTM standard. Recently, the ISO incorporated the 8-mm striker into the standards in addition to the 2-mm striker. This situation can present difficulties for manufacturers of materials and structures which are required to meet minimum specified CVN impact toughnesses according to, for example, the ASTM (which allows only the 8-mm striker), but they have data available from tests conducted with the 2-mm striker. Likewise, for codes and standards organizations, adoption of materials based on data obtained with the 2-mm striker into a code which references the ASTM specification presents a dilemma. Towers [3] tested verification specimens from the Army Mechanics and Materials Research Center (AMMRC) and nine other materials (e.g., aluminum alloys, aluminum-bronze, stainless steels, carbon steel, $5 \% \mathrm{Ni}$ and $9 \%$ Ni steels) with the two different strikers. For the verification specimens, which ranged in nominal absorbed energies up to $107 \mathrm{~J}$, the two strikers gave equivalent energies. For the nine other materials, he observed equivalent results up to about $60 \mathrm{~J}$, as shown in Fig. 2. Above that energy, however, although the 8-mm striker showed generally higher energies, the energies at which the differences were observed and the magnitudes of the differences were material dependent. Naniwa [4] tested carbon and low-alloy steels and, as shown in Fig. 3(a), observed general equivalence up to about $200 \mathrm{~J}$; above that level, the 8-mm striker gave higher energies with the differences increasing with increasing energy. Naniwa stated no differences were observed in lateral expansion, percent shear, or transition temperature. The data from Ref. 4, however, shown in Fig. 3(b), appear to show a general deviation from equivalence with the 2 -mm striker showing a tendency for greater expansion. Revise [5] tested "metallic samples" at a few different energy levels and observed equivalence up to about $100 \mathrm{~J}$; at the level of $160 \mathrm{~J}$ for the $2-\mathrm{mm}$ striker, however, the $8-\mathrm{mm}$ striker gave about $165 \mathrm{~J}$. The Heavy-Section Steel Irradiation (HSSI) Program at Oak Ridge National Laboratory (ORNL) is involved in two cooperative projects that include international participants. For both projects, CVN impact tests were performed with both the 2-mm and 8-mm strikers; one objective of both projects was to compare the results from the two strikers with different materials and, where practicable, with enough tests for statistical evaluations. 


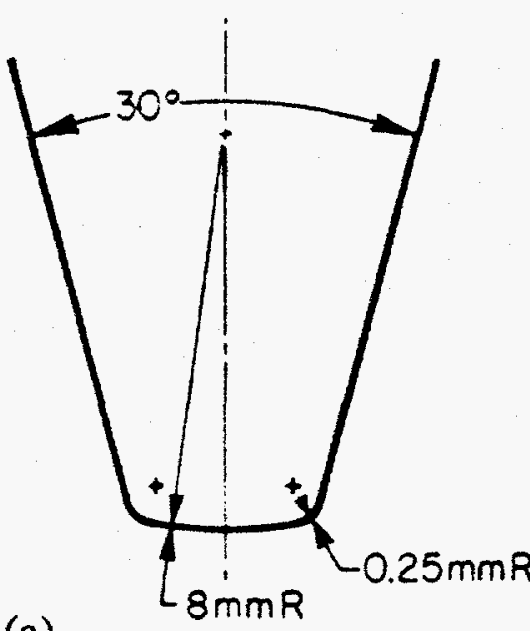

(a)

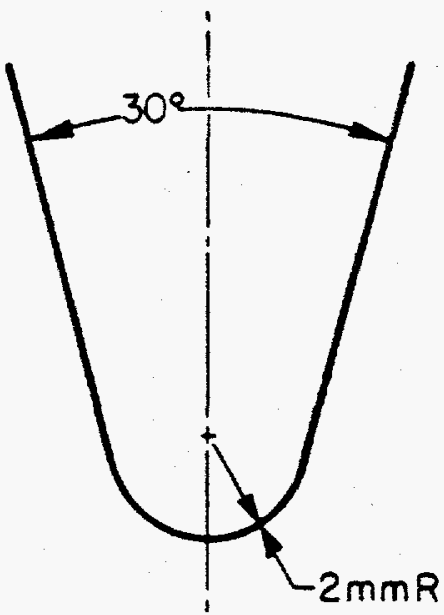

(b)

FIG. 1. Schematic drawing showing the differences in the striking ends of the (a) 8-mm and (b) 2-mm radius Charpy impact strikers. The 8-mm striker is thicker and has a substantially larger radius of curvature and relatively sharp edges.

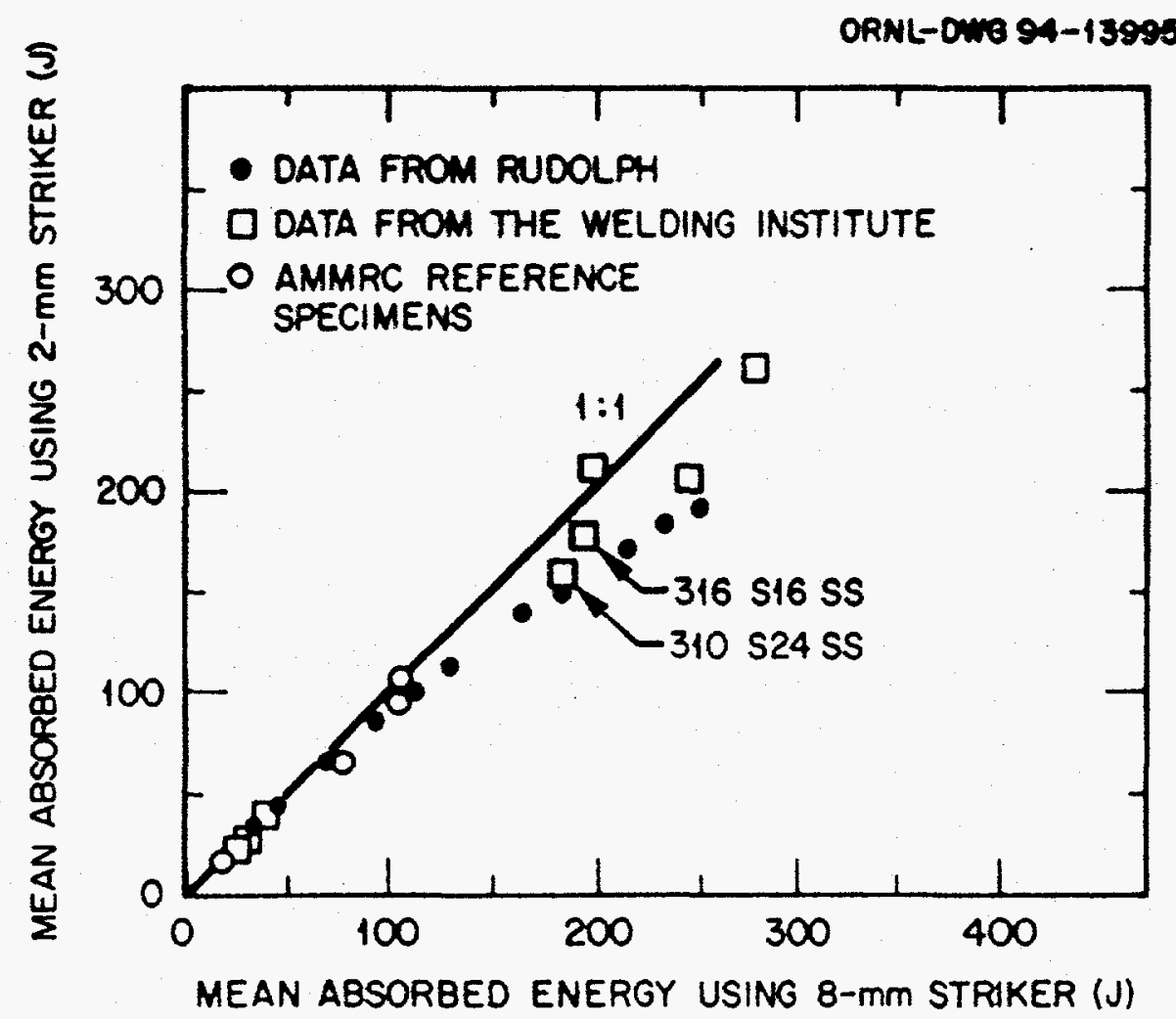

FIG. 2. Plot of data from Tower showing effect of striker shape on absorbed energy in Charpy impact test for different materials. 


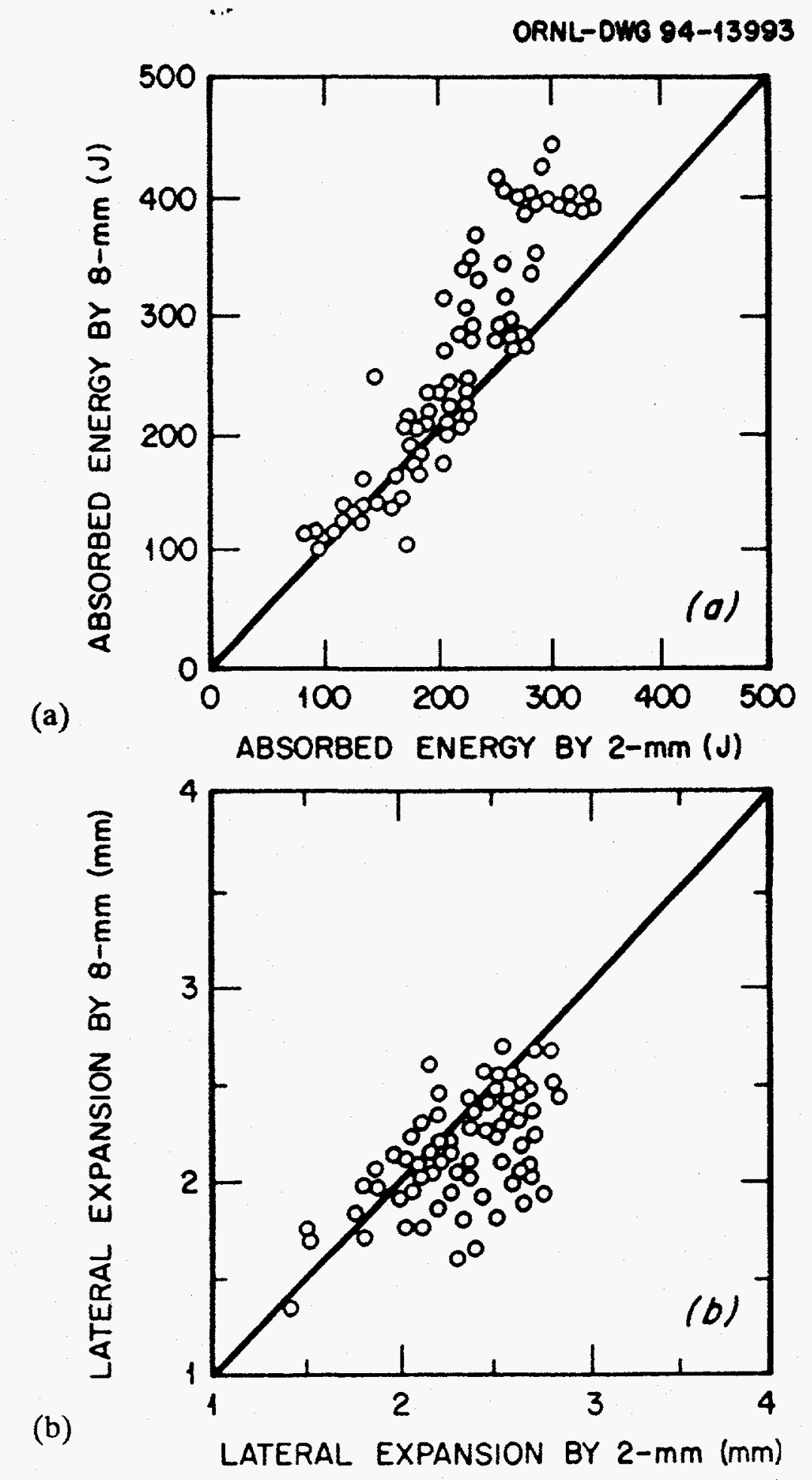

FIG. 3. Plot of data from Naniwa for carbon and low-alloy steel: (a) general equivalence of energy values for the two strikers was observed to about $200 \mathrm{Nm}(\mathrm{J})$ with the 8-mm striker measuring higher energies than the 2-mm striker above that level, and (b) tests with the 2-mm striker appear to exhibit a tendency for greater expansion values. 


\section{MATERIALS AND PROCEDURES}

Table 1 summarizes the test matrix for the various materials. Verification of 4340 high-strength steel from the National Institute of Standards and Technology (NIST) were tested at ORNL on the same machine using the 2-mm and 8-mm strikers. Two different heats of A 533 grade B class 1 low-alloy (Mn-Mo-Ni) pressure vessel steel plate and a low upper-shelf (LUS) submerged-arc (SA) weld (Mn-Mo-Ni) were tested on the same Charpy machine, while one heat of a Russian forging steel (Cr-Mo-V) and a high upper-shelf (HUS) SA weld (Mn-Mo-Ni) were tested on three different machines, one at ORNL with the 8-mm striker and two in Russia with the 2-mm striker. One of the heats of A 533 grade B (HSST Plate 13) was also tested on two machines in Russia with the 2 -mm striker. Tests were conducted at four temperatures for one plate, while two test temperatures were used for the other plate and the LUS weld. Table 2 provides the room temperature tensile properties of the five steels tested, respectively. The number of replicate tests were quite variable and were dependent on the specific program of testing. In some of the cases, the number of tests were relatively high, (e.g., 23 and 46 ) which provides for reasonable credibility from a statistical basis.

In most of the cases shown in Table 1 for ORNL, tests were conducted to provide direct comparison of results with the two strikers on the same Charpy machine. Prior to testing of these materials with each striker, verification specimens at the low, high, and super high energy levels from NIST were tested. These specimens are designed to be applicable to the verification of a pendulum impact machine with the 8-mm striker. The energy levels are specified in English units and are nominally about 12,75 , and $160 \mathrm{ft}-\mathrm{lb}$ (about 16,102 , and $217 \mathrm{~J}$ ), respectively, with the actual values dependent on the particular heat of steel used to produce the supply of specimens. For the verification testing, five specimens from each energy level are tested. For each level, the average energy of the five tests must be within a specified deviation from a specified mean value supplied by NIST for the heat of material used. The general procedure followed in this series of experiments was, (1) verification with the $8-\mathrm{mm}$ striker, (2) verification with the $2-\mathrm{mm}$ striker, (3) testing of test materials with the 2-mm striker, (4) verification with the 8-mm striker, and (5) testing of test materials with the 8-mm striker. This procedure was designed to provide assurance that the machine stayed in calibration throughout the series of tests and striker changes.

For the testing at ORNL, a 326-J (240-ft-lb) capacity pendulum-type impact machine, Baldwin Model SI1C, was used. Both the 8-mm and 2-mm strikers are instrumented with strain gages to provide a load-time record, but all energy values reported herein were obtained from the dial energy. The machine is equipped with a semiautomated specimen thermal conditioning and transfer system. The transfer system places the specimen in the thermal conditioning system which heats the specimen by contact with graphite electrodes, cools the specimen with cold nitrogen gas, and includes a calibrated contact thermocouple for temperature measurement. The transfer system allows for transfer of the specimen to the anvils for testing in less 
TABLE 1--Number of test temperatures, machines, and replicate tests for the tested materials

\begin{tabular}{|c|c|c|c|}
\hline Material & $\begin{array}{l}\text { Number of } \\
\text { temperatures }\end{array}$ & $\begin{array}{c}\text { Test } \\
\text { laboratories }\end{array}$ & Replicates \\
\hline A533B (HSST-03) & 2 & ORNL & $\begin{array}{l}\text { 2-mm: } 23 / 46 \\
\text { 8-mm: } 23 / 46\end{array}$ \\
\hline AS33B (HSST-13) & 3 & ORNL & $\begin{array}{l}\text { 2-mm: } 10 / 20 \\
\text { 8-mm: } 10 / 20\end{array}$ \\
\hline A533B (HSST-13) & $\begin{array}{l}4 \\
4\end{array}$ & $\begin{array}{l}\text { RUSSIA } \\
\text { ORNL }\end{array}$ & $\begin{array}{ll}2-\mathrm{mm}: & 2-5 \\
8-\mathrm{mm}: & 2-5\end{array}$ \\
\hline $\begin{array}{l}\text { HUS weld } 72 W \\
\text { HUS weld } 72 W\end{array}$ & $\begin{array}{l}4 \\
4\end{array}$ & $\begin{array}{l}\text { ORNL } \\
\text { RUSSIA }\end{array}$ & $\begin{array}{l}\text { 8-mm: } 6-10 \\
\text { 2-mm: } 2-5\end{array}$ \\
\hline LUS weld & 2 & ORNL & $\begin{array}{l}\text { 2-mm: } 23 / 46 \\
\text { 8-mm: } 23 / 46\end{array}$ \\
\hline $\begin{array}{l}\text { 15Kh2MFA forging } \\
\text { 15Kh2MFA forging } \\
\text { 15Kh2MFA forging } \\
\text { 15Kh2MFA forging }\end{array}$ & $\begin{array}{l}7 \\
7 \\
2 \\
2\end{array}$ & $\begin{array}{l}\text { ORNL } \\
\text { RUSSIA } \\
\text { ORNL } \\
\text { RUSSIA }\end{array}$ & $\begin{array}{ll}\text { 8-mm: } & 4-6 \\
2-m m: & 4-6 \\
\text { 8-mm: } & 10 \\
2-m m: & 10\end{array}$ \\
\hline $\begin{array}{l}\text { NIST verification } \\
\text { ( } 3 \text { energy levels) }\end{array}$ & 1 & ORNL & $\begin{array}{l}\text { 2-mm: } 3 \text { sets } \\
\text { 8-mm: } 5 \text { sets }\end{array}$ \\
\hline
\end{tabular}

TABLE 2-Tensile properties of tested materials at room temperature

\begin{tabular}{|l|c|c|}
\hline \multicolumn{1}{|c|}{ Material } & $\begin{array}{c}\text { Yield strength } \\
(\mathrm{MPa})\end{array}$ & $\begin{array}{c}\text { Ultimate strength } \\
(\mathrm{MPa})\end{array}$ \\
\hline A533B (HSST-03) & 460 & 618 \\
A533B (HSST-13) & 424 & 600 \\
SAW, Linde 80 & 500 & 603 \\
SAW HSSI weld 72W & 500 & 609 \\
15Kh2MFA forging 103672 & 630 & 680 \\
\hline
\end{tabular}


than $5 \mathrm{~s}$ following removal from the conditioning chamber. Figure 4 shows a composite photograph of the system (photo shows a different Charpy machine). The percent shear fracture was visually measured and the lateral expansion was measured with a device similar to that described in ASTM E-23. For the testing in Russia, a 300-J (221-ft-lb) capacity pendulum-type machine, Amsler Model RKP-300 was used; only the 2-mm striker was used for those tests. Calibration of that machine was performed by direct methods of alignment, etc. by the official state standardization committee of Russia.

\section{RESULTS}

\section{Verification Specimens}

Figure 5 summarizes the results of NIST verification specimen tests for both the 8-mm and 2-mm strikers in terms of deviation from the NIST supplied nominal mean values for each particular set of specimens tested. The 8-mm striker met the specified requirements at all three energy levels in all cases. The 2-mm striker met the requirements in all cases for the low and high energy levels but not at the super high level, with the average energies being about $25 \mathrm{~J}$ (about 11\%) below the nominal mean values. The nominal mean values for verification are supplied for the 8-mm striker only.

\section{Low-Alloy Steels}

For tests conducted with HSST Plate 13 to directly compare the two strikers, 10 tests with each striker were conducted at $-60^{\circ} \mathrm{C}$ and $150^{\circ} \mathrm{C}$, while 20 tests with each were conducted at $0^{\circ} \mathrm{C}$. Figure $6(\mathrm{a})$ shows the average energies, as well as the minimum and maximum values, and two standard deviations for each case. Somewhat surprisingly, tests with the $2-\mathrm{mm}$ striker showed generally higher energies at all three temperatures. The differences, however, are within one standard deviation in each case. The lateral expansion results exhibit a similar comparison, Fig. 6(b). The percent shear fracture results are the same for the two studies, Fig. 6(c). Figure 6(d) shows the definite trend for the $2-\mathrm{mm}$ striker to result in somewhat higher lateral expansion per unit of absorbed energy. Tests with HSST Plate 13 were also conducted in a separate study on different machines, one at ORNL and two in Russia. Figure 7 shows the same trend as obtained with a large number of tests on the ORNL machine (Fig. 6); the tests with the 2-mm striker exhibited somewhat higher average energies, although these results also revealed overlap within one standard deviation. Thus, all the results with that material show consistent comparisons.

In two other similar studies to compare results on different machines in the United States (8-mm striker) and Russia (2-mm striker), Figs. 8 and 9 show somewhat mixed results. Although the results in Fig. 9 would appear to indicate that the 2-mm striker gives much higher results, the data were highly scattered for this Russian $\mathrm{Cr}-\mathrm{Mo}-\mathrm{V}$ forging steel, and the average values did overlap within one 


\section{COMPUTER INTERACTIVE CHARPY TESTING SYSTEM}

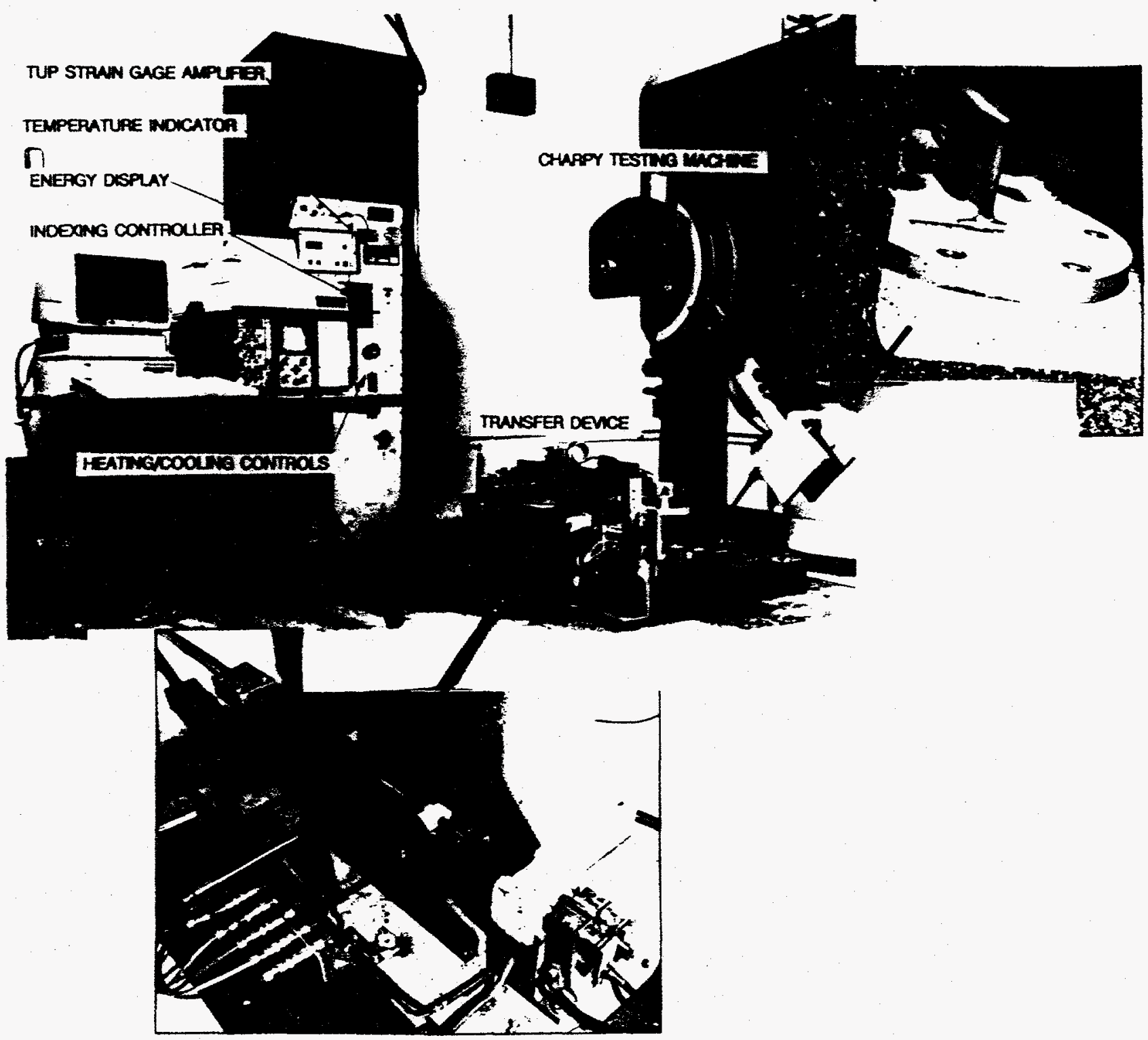

FIG. 4. Composite photograph of the ORNL Charpy impact system used to conduct the striker comparisons. 
OANL-DWG 91Z-13592

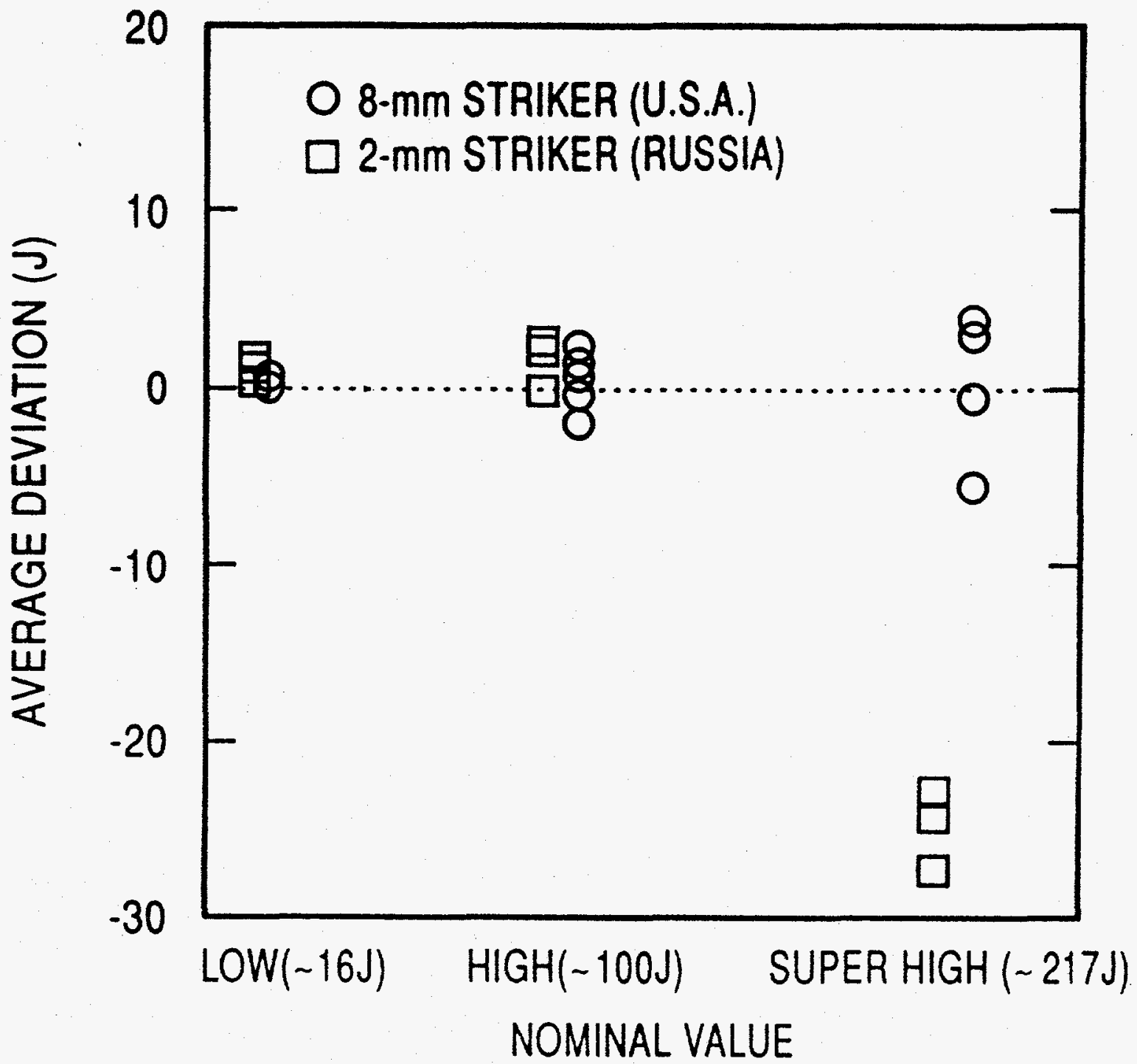

FIG. 5. Plot of average deviation from nominal values for $2-\mathrm{mm}$ and $8-\mathrm{mm}$ strikers at three nominal energy levels supplied by NIST for the 8 -mm striker. 

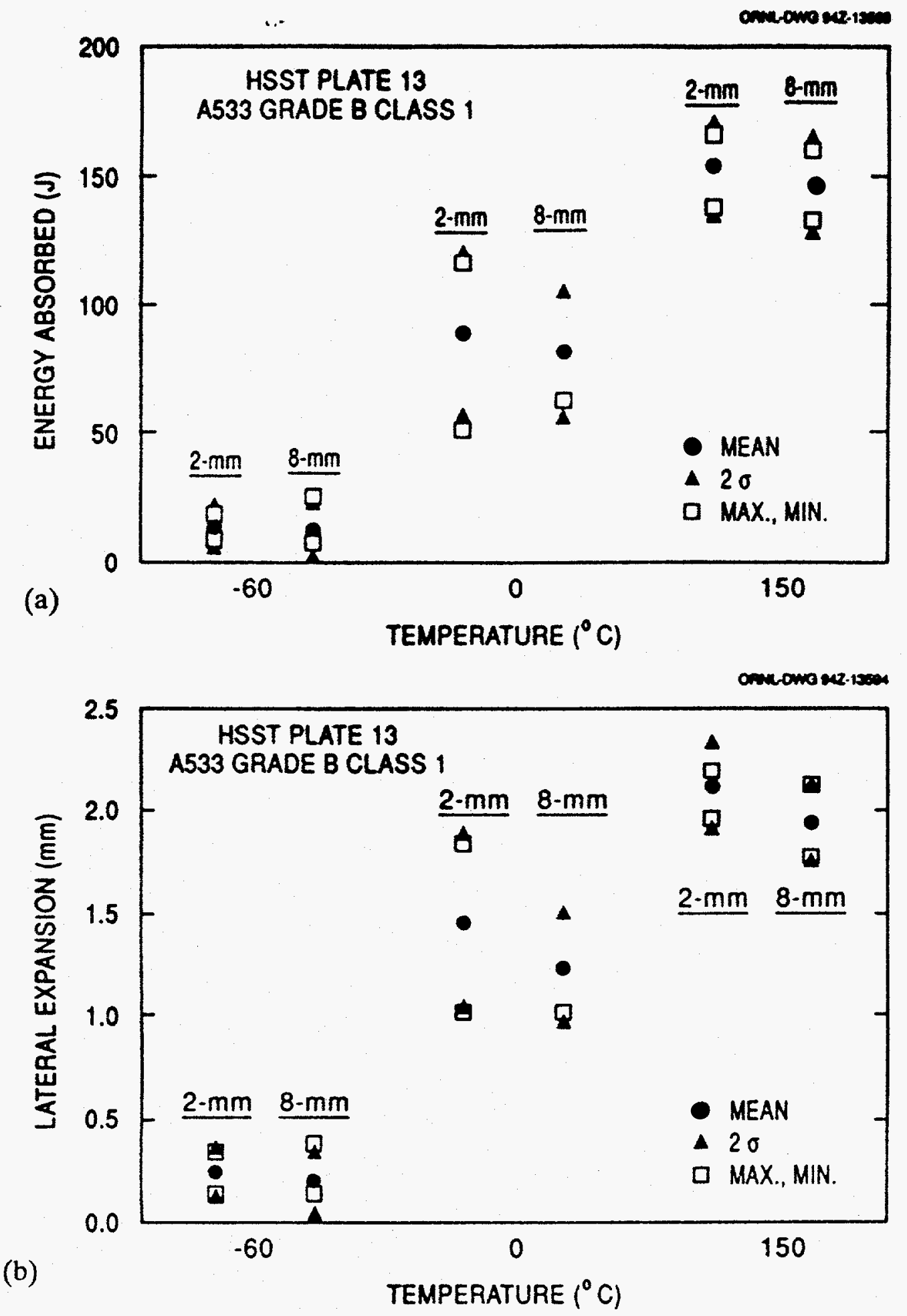

FIG. 6. Plots of ORNL data for Charpy impact tests at three temperatures for A 533 grade B class 1 steel (HSST Plate 13) conducted with both $2-\mathrm{mm}$ and 8-mm strikers: (a) average absorbed energy, (b) average lateral expansion, (c) average percent shear, and (d) absorbed energy versus lateral expansion. 

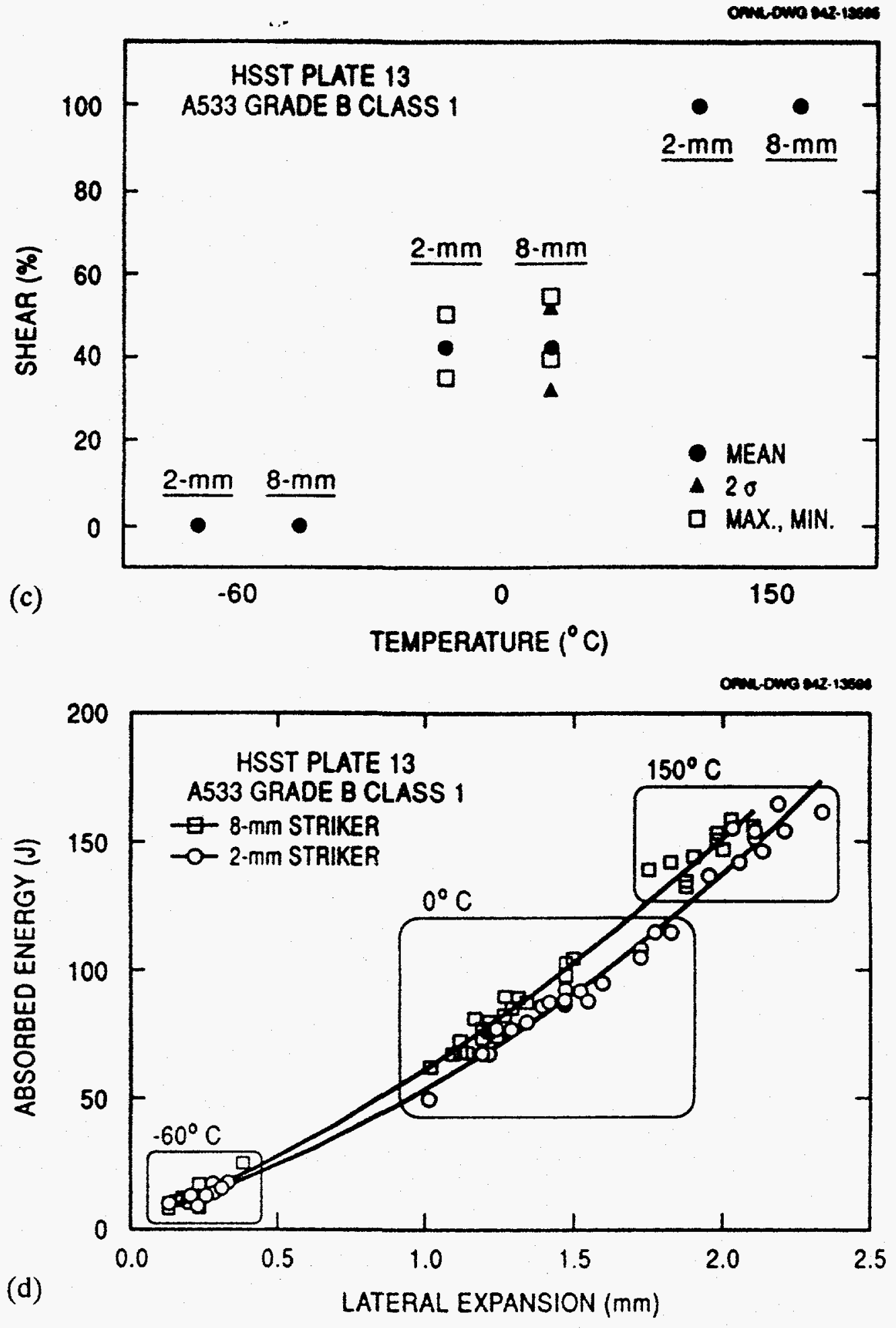

FIG. 6. (Continued) 
ORNL-DWG 94Z-13597

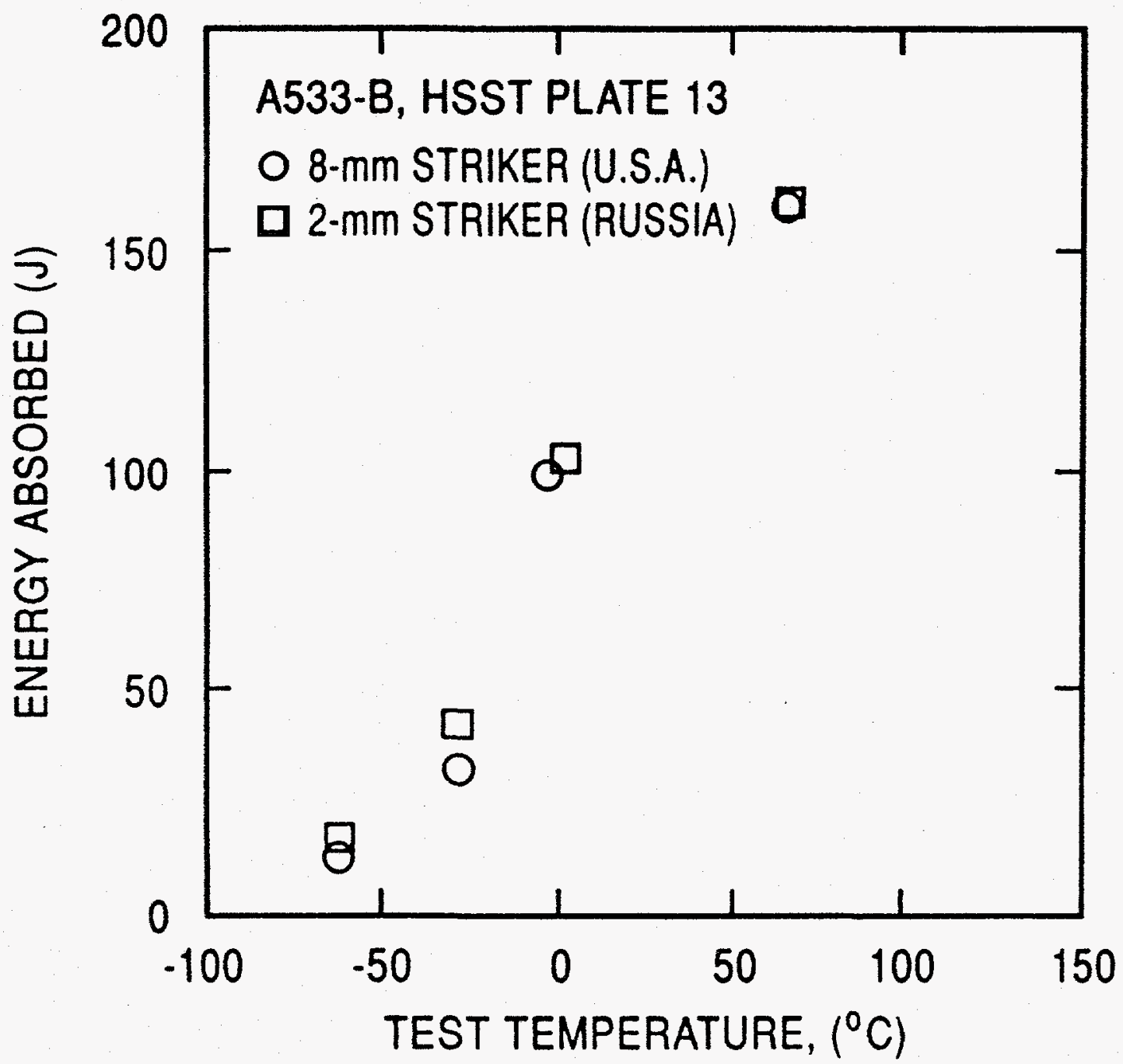

FIG. 7. Plot of average Charpy impact absorbed energy versus temperature for A 533 grade B class 1 steel (HSST Plate 13) tested on different machines in the United States (8-mm striker, one machine) and Russia (2-mm striker, two machines). 


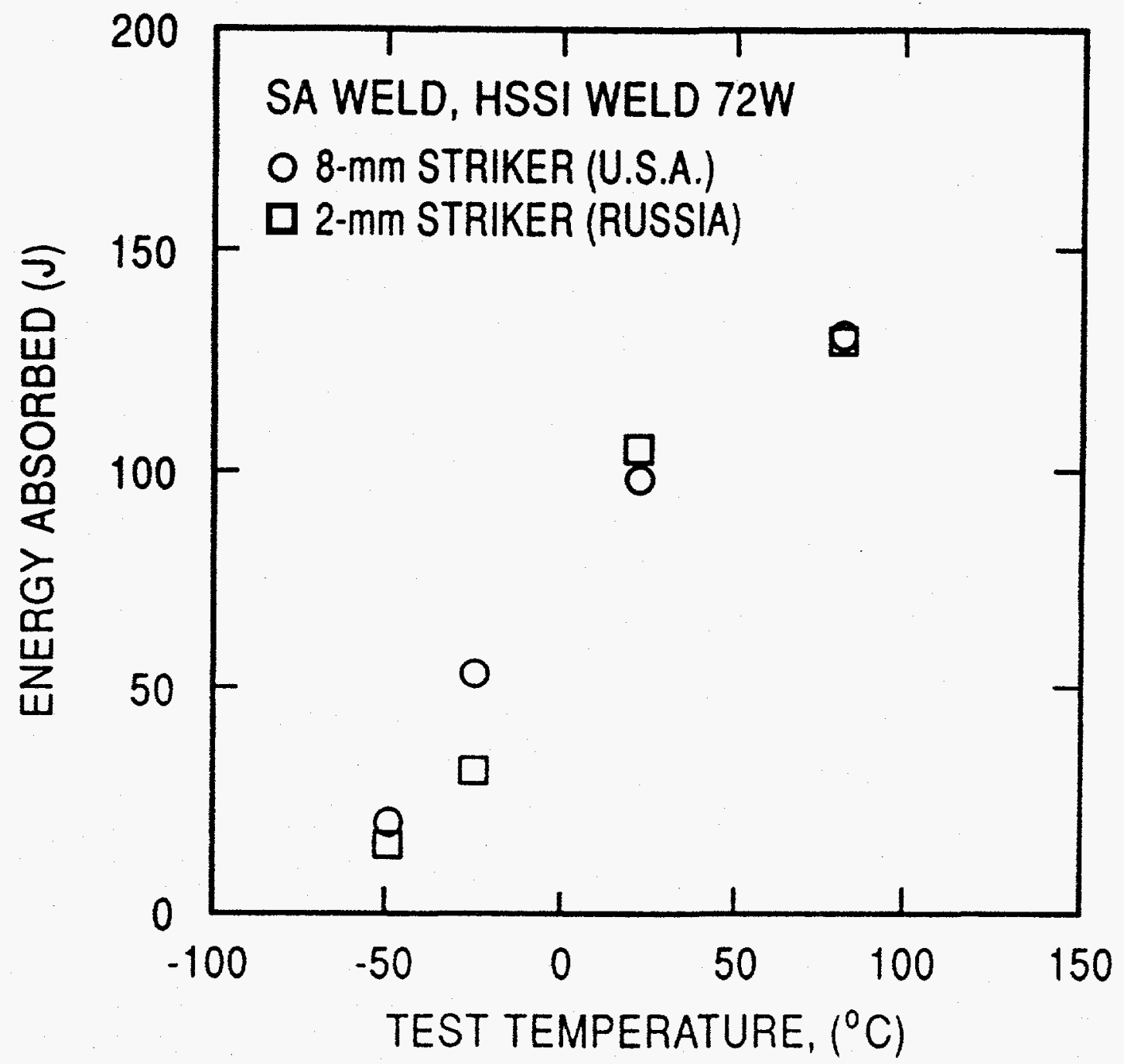

FIG. 8. Plot of average Charpy impact absorbed energy versus temperature for high-copper, high upper-shelf SA weld tested on different machines in the United States (8-mm striker) and Russia (2-mm striker). 


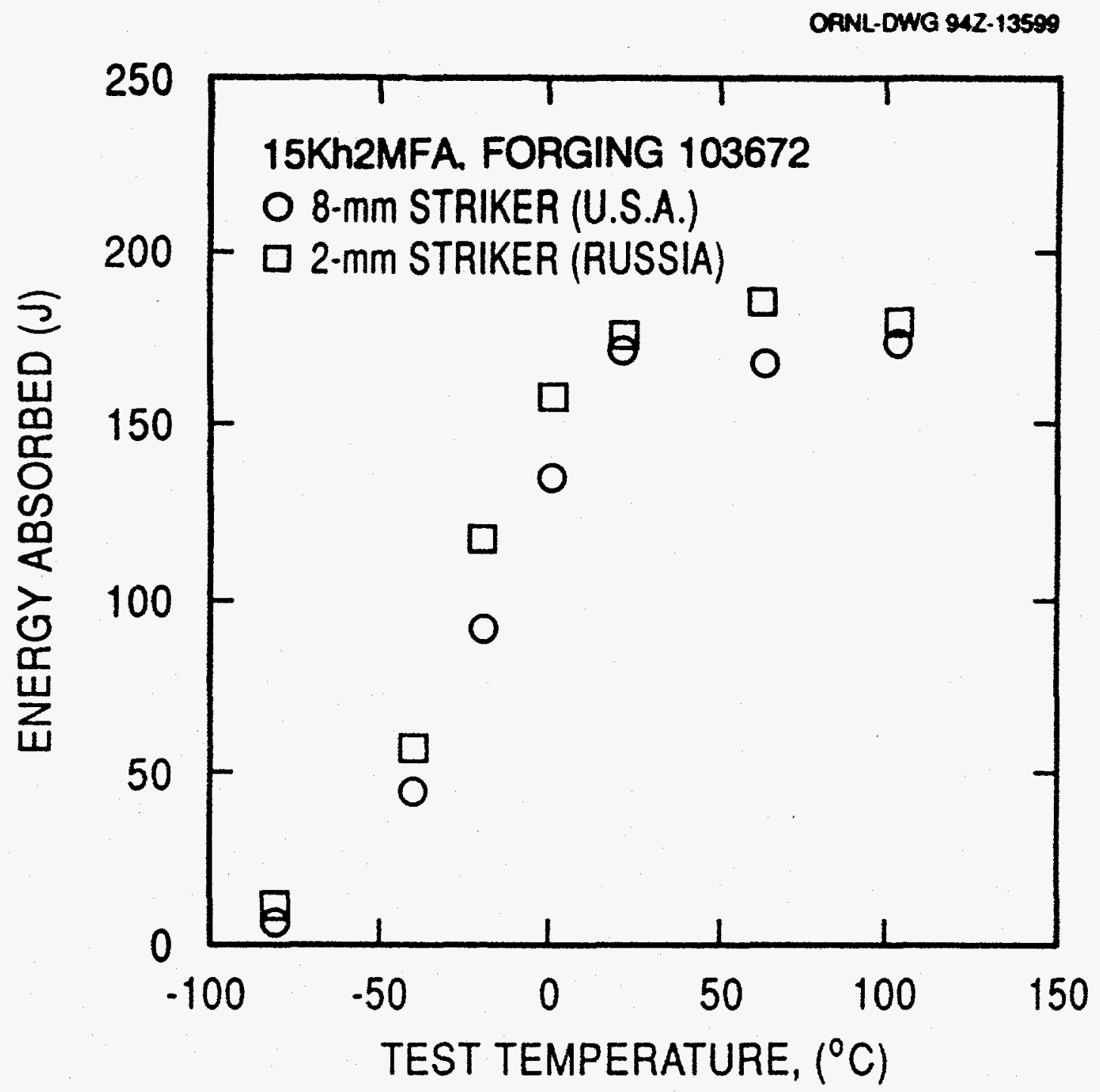

FIG. 9. Plot of average Charpy impact absorbed energy versus temperature for a Russian forging steel ( $\mathrm{Cr}-\mathrm{Mo}-\mathrm{V}$ ) tested on different machines in the United States (8-mm striker) and Russia (2-mm striker). 
standard deviation. Even so, the tendency in that case is, as with HSST Plate 13, for the 2-mm striker to measure somewhat higher energies.

In a separate study on the same ORNL test machine, a relatively large number of specimens were tested with each striker, 46 at the low temperature and 23 at the high temperature for a plate steel and a SA weld. The A 533 grade B steel (HSST Plate 03) was tested at -12 and $93^{\circ} \mathrm{C}\left(10\right.$ and $\left.200^{\circ} \mathrm{F}\right)$, while the high-copper low upper-shelf SA weld was tested at 2 and $93^{\circ} \mathrm{C}\left(35\right.$ and $\left.200^{\circ} \mathrm{F}\right)$. Figures $10(\mathrm{a})$ and 10(b) show the average absorbed energies and lateral expansions. The results from the two strikers are very comparable at the three lower energy levels. At the $\approx 160-\mathrm{J}$ level, the 8-mm striker results are somewhat higher but, again, they are within one standard deviation. The lateral expansion results are similar except the 2-mm striker has a tendency for the higher value at the higher temperature.

\section{DISCUSSION OF TEST RESULTS}

Prior to conducting the testing described above, it was anticipated that, for the steels included in the testing programs, the 8-mm striker would be observed to measure higher energies, especially at temperatures where the specimen bending and plastic deformation were relatively high. Figure 11, however, shows general equivalence of the absorbed energy results up to almost $200 \mathrm{~J}$. There is scatter about the 1:1 equivalence, but all the results are within two standard deviations of the equivalence line. For the lateral expansion measurements, a linear fit to the overall data shows that tests with the $2-\mathrm{mm}$ striker tend to give about $8 \%$ higher values.

The expectation of higher energy measurements with the 8-mm striker was based not only on previous results (e.g., Ref. 4) and the rationale that higher energy would be measured by a striker with a large radius when the specimen bending is sufficient, but also on observations from load-time record comparisons. Figure 12 shows the original load-time records at two temperatures for A 533 grade B steel (HSST Plate 13) for both the instrumented 2-mm and 8-mm strikers. For this comparison, the specific specimen records were chosen because the two strikers measured the same absorbed energy in each case. In Figs. 12(a) and (b), the records are comparable, although the 8-mm striker appears to have a somewhat greater increase in load from the point of general yielding to maximum load. Other comparisons have not yet been conducted to ascertain if that is a general observation. At the higher temperature, however, a comparison of Figs. 12(c) and (d) show that the 8-mm striker load-time record includes a region near the end of the test whereby the rate of load decrease is substantially reduced for about $1.5 \mathrm{~ms}$. If the absorbed energy were obtained from the load-time record, that feature would result in a higher energy determination due to the additional area under the curve. This feature is associated with increased loading on the striker from the specimen "wrapping around" the striking edge and/or, if the bending angle is very high, the specimen being forced through the anvils with a resultant side loading. The load-time record for the $2-\mathrm{mm}$ striker does not indicate such a change in the loading of the striker. It is assumed that all interactions between the specimen, striker, and/or anvils would undoubtedly 

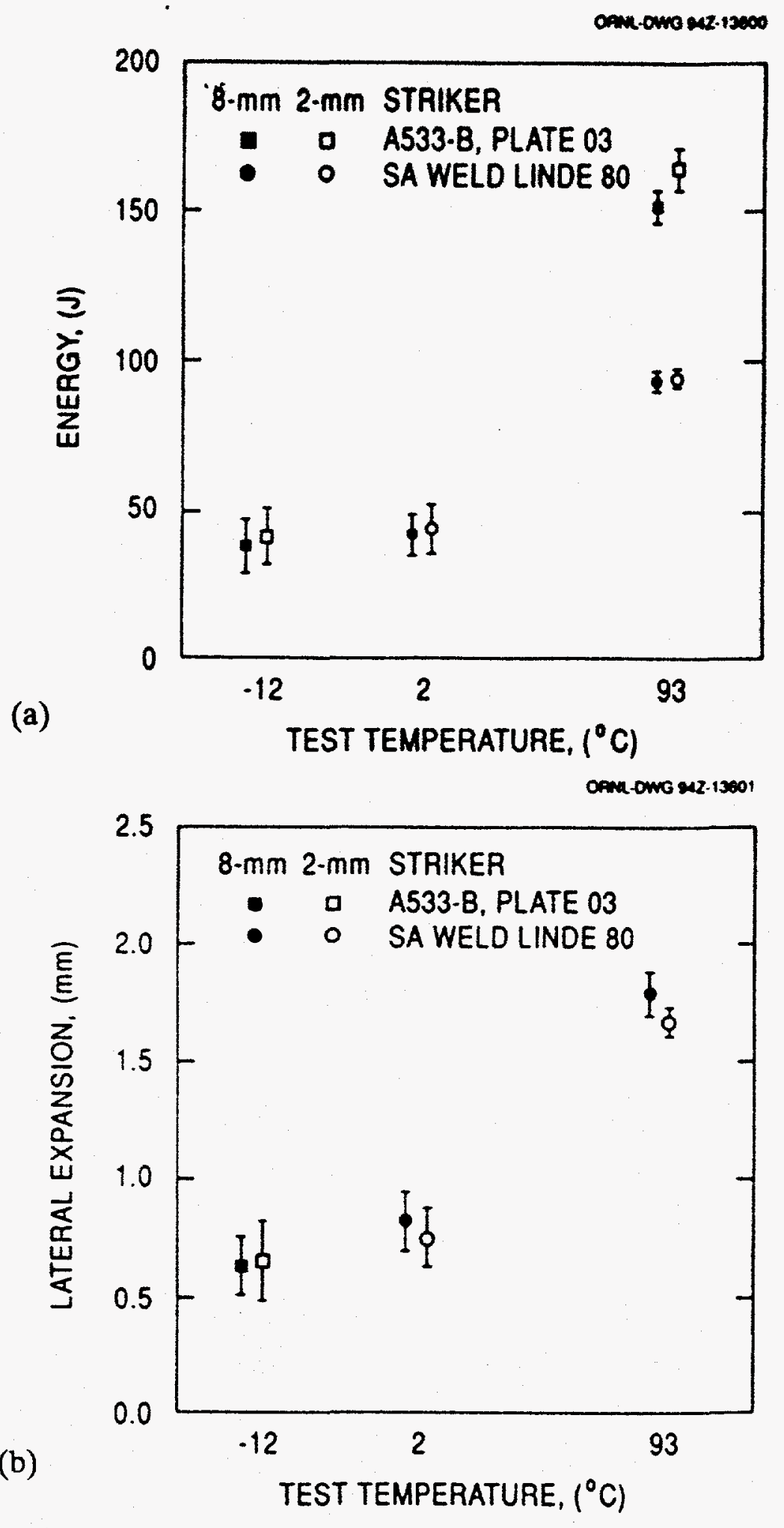

FIG. 10. Plot of average Charpy impact (a) absorbed energy, and (b) lateral expansion, versus temperature for A 533 grade B class 1 steel (HSST Plate 03) and a high-copper, low upper-shelf SA weld conducted with both $8-\mathrm{mm}$ and 2-mm strikers. For each striker and each material, 46 tests were conducted at the low temperature and 23 tests at the high temperature. 

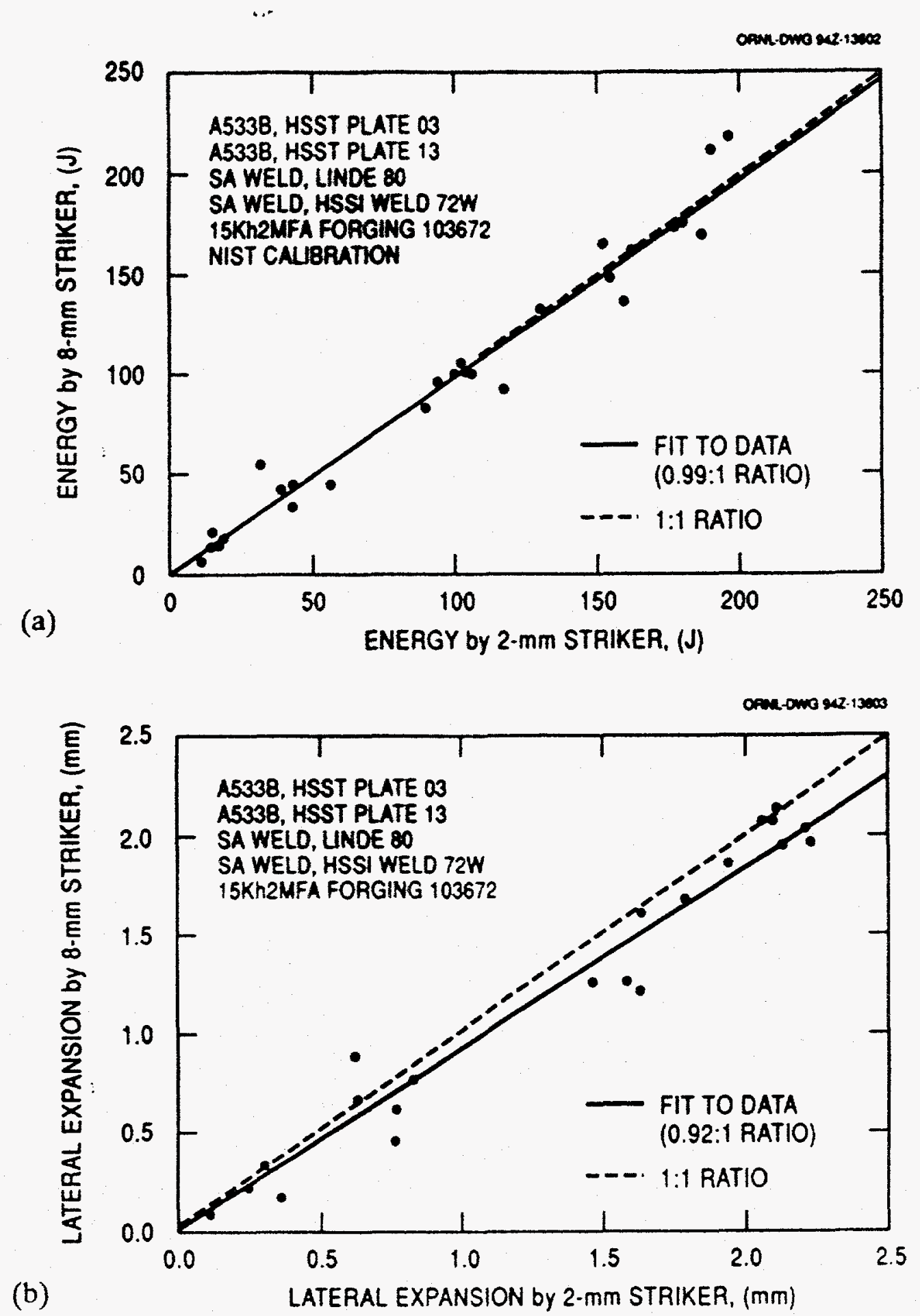

FIG. 11. Plot of average Charpy impact (a) absorbed energy, and (b) lateral expansion, versus temperature for all the steels tested. Some of the results represent direct comparisons of the two strikers on the same machine while others are based on comparisons from different machines in the United States (8-mm striker) and Russia (2-mm striker). 


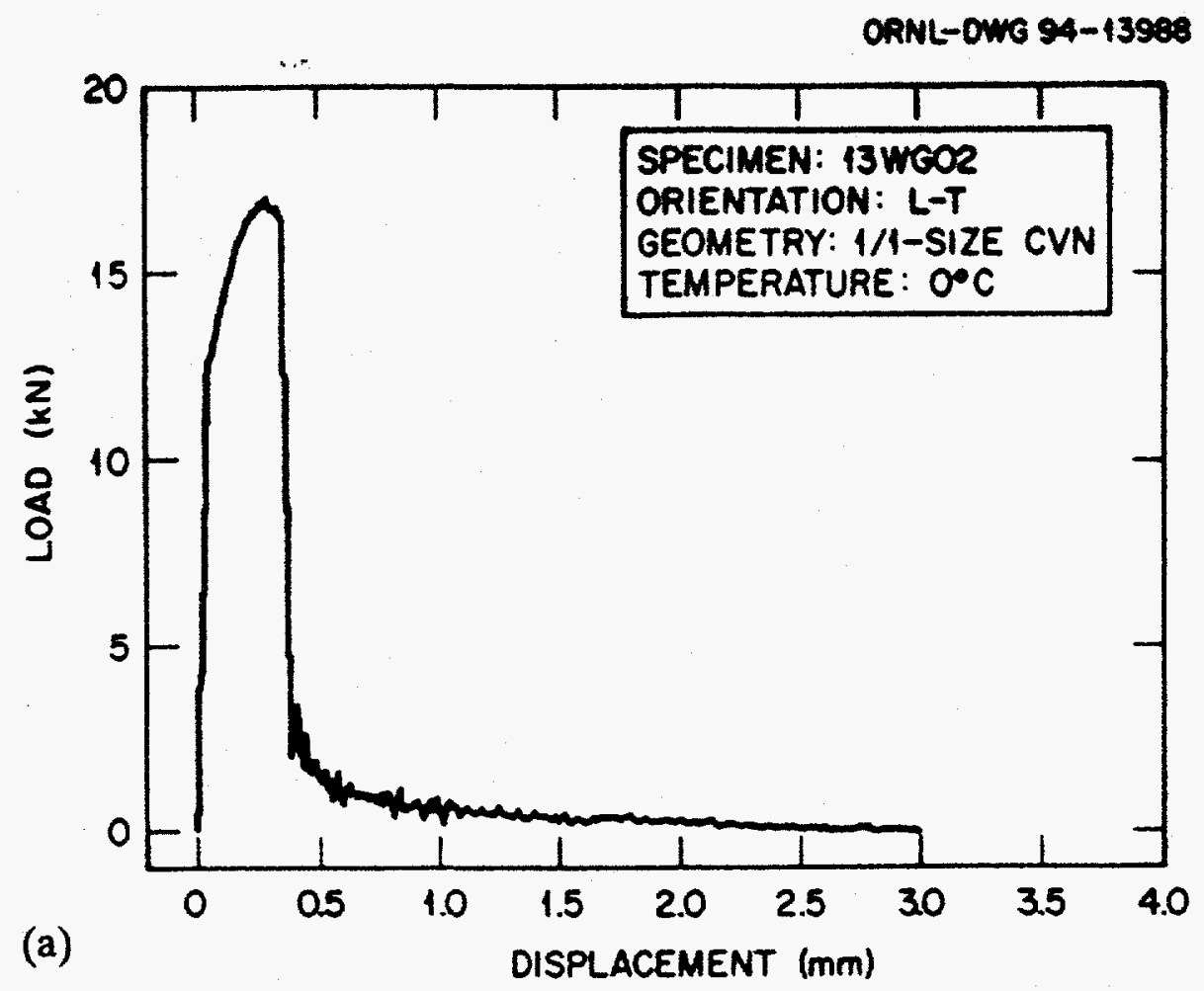

ORNL-ONG 94-13999

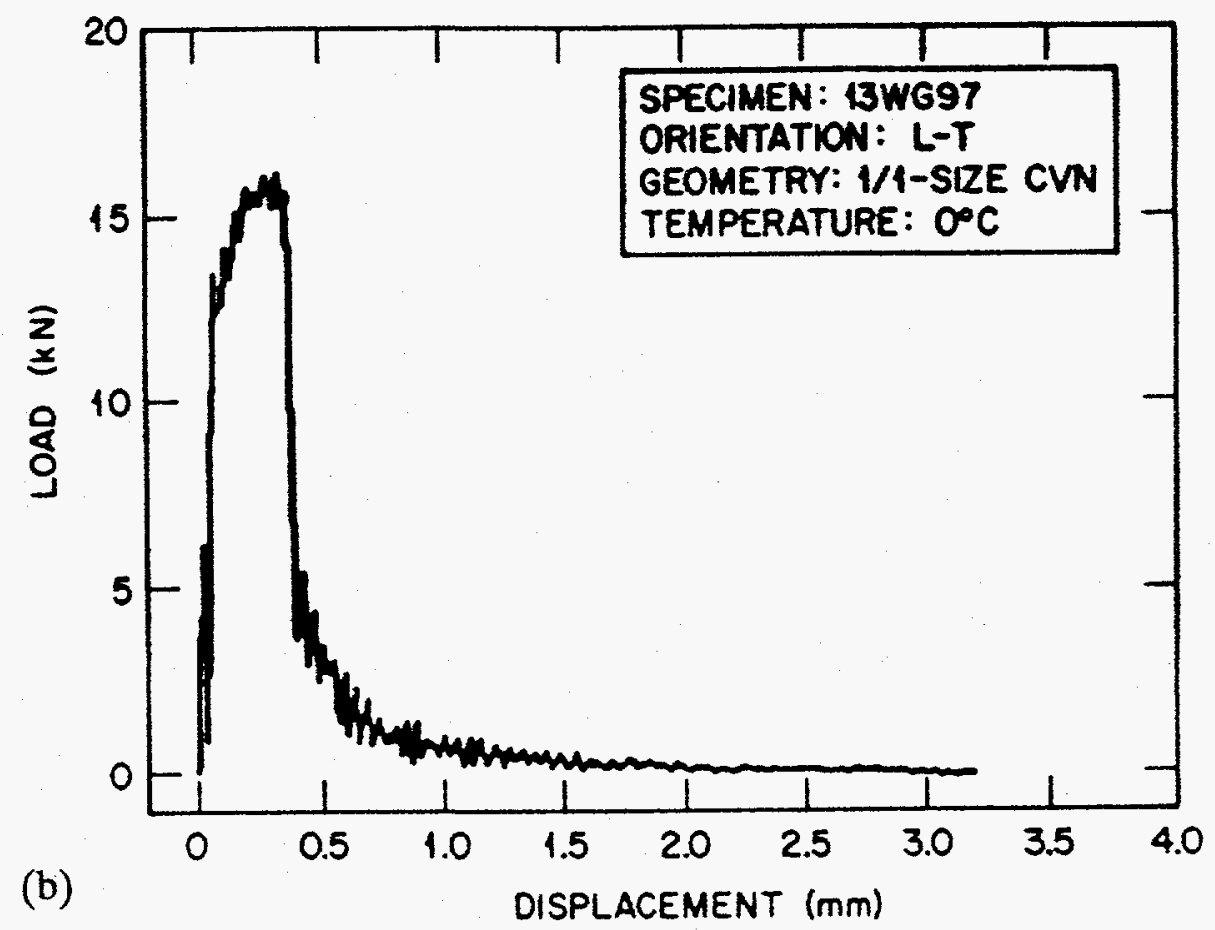

FIG. 12. Load-time records from Charpy impact tests with A 533 grade B class 1 steel (HSST Plate 13) at two temperatures with both the 8-mm and 2-mm strikers: (a) $8-\mathrm{mm}$ at $0^{\circ} \mathrm{C}$, (b) $2-\mathrm{mm}$ at $0^{\circ} \mathrm{C}$, (c) $8-\mathrm{mm}$ at $150^{\circ} \mathrm{C}$, (d) $2-\mathrm{mm}$ at $150^{\circ} \mathrm{C}$. At $0^{\circ} \mathrm{C}$, both tests showed $78-\mathrm{J}$ energy, while at $150^{\circ} \mathrm{C}$, both tests showed $157 \mathrm{~J}$. 


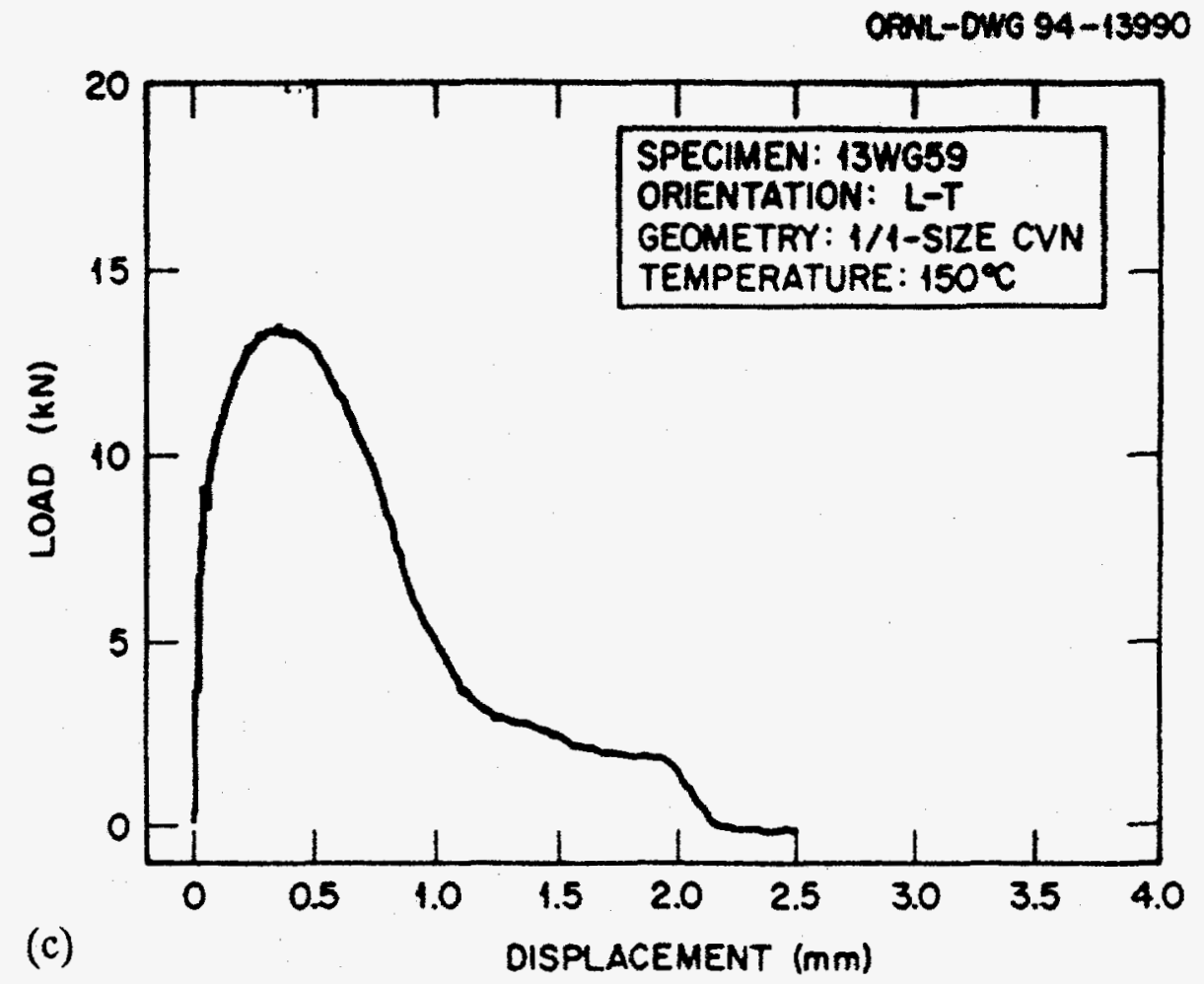

ORNL-OWG 94-13991

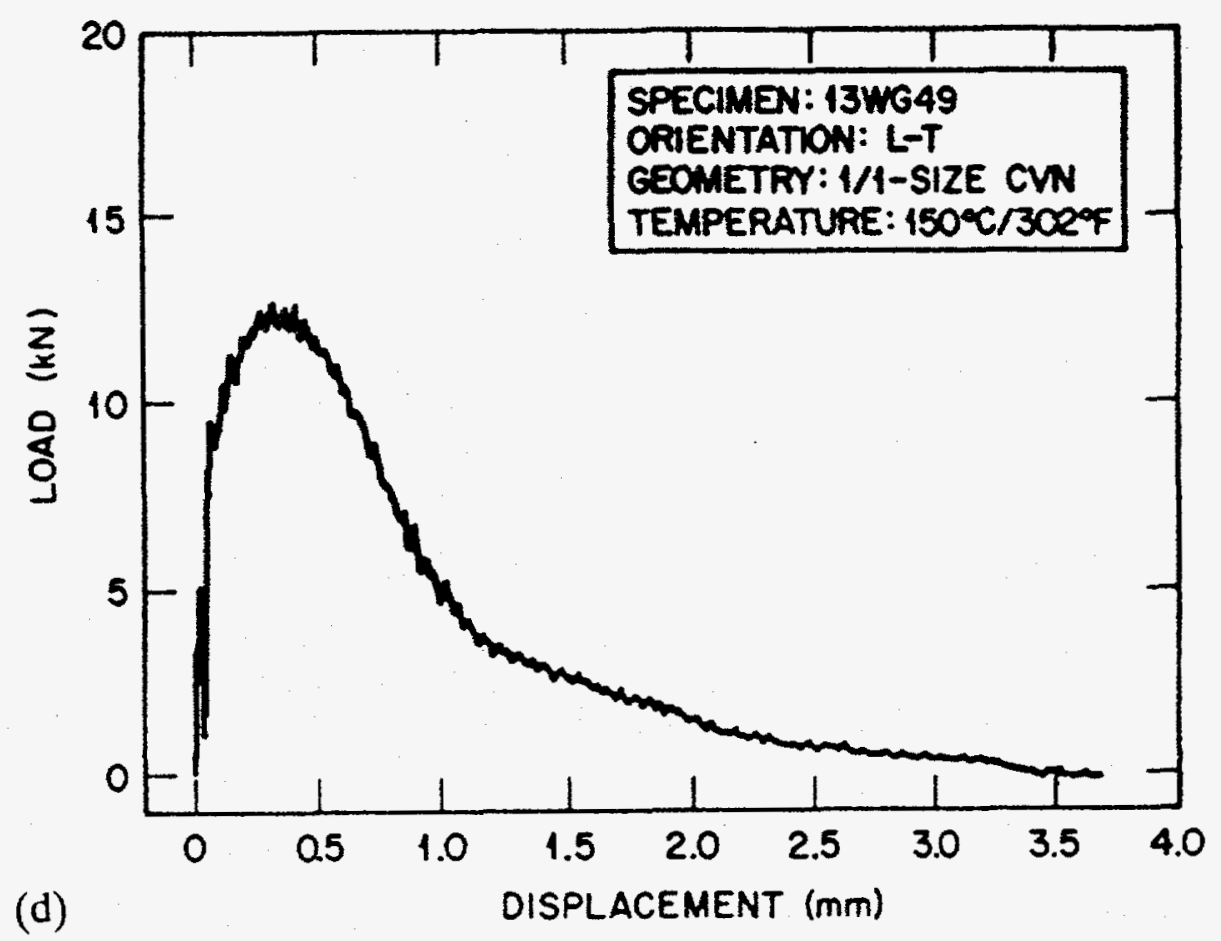

FIG. 12. (Continued) 
result in additional energy reflected by the machine dial. This observation does not explain the case presented earlier where the 2-mm striker showed a tendency to measure higher energy. Other factors, such as deeper penetration of the smaller striker into the test material and effects of more localized plastic deformation, may contribute to these observations. Differences in tensile properties, strength, and strain hardening, for example, likely contribute to a material-specific rationale for some of the observed results. This also applies to the lateral expansion observations. An analysis of all the test results regarding the load-time records, bending analyses, etc., has not yet been performed.

\section{ESTTMATION OF SHEAR FRACTURE PERCENTAGE}

Determination of the percentage of shear fracture is based on the measurement of the cleavage portion of the fracture surface of broken Charpy V-notch (CVN) specimens and comparison with the full fracture surface by any of four methods given in E-23 [1]. The disadvantage of such a procedure is the dependence of the measured percentage of shear on interpretation of the cleavage portion of the fracture surface which can vary from person to person. For example, the fracture surfaces of CVN specimens representing weld metal of reactor pressure vessels can be particularly difficult to interpret. In-service surveillance programs require the performance of tests remotely. Thus, the remote measurement of the percentage of shear on the fracture surface of irradiated specimens can be even more complicated. As a result, some researchers have attempted to develop a more objective and simple procedure by analyzing the instrumented CVN impact trace $[6,7]$. The main idea of that approach is based on association of the cleavage part of the fracture with the fast load drop observed on the load-time diagram of an instrumented CVN test. Moreover, the European Structural Integrity Society (ESIS) has prepared a draft of a standard method for the instrumented CVN test on metallic materials [8], which allows one to estimate an approximate value of the proportion of ductile fracture surface by using one of the following formulae:

$$
\begin{aligned}
& \text { \% shear }=\left[1-\left(\mathrm{P}_{\mathrm{iu}}-\mathrm{P}_{\mathrm{a}}\right) / \mathrm{P}_{\mathrm{m}}\right] \times 100 \%, \\
& \% \text { shear }=\left[1-\left(\mathrm{P}_{\mathrm{iu}}-\mathrm{P}_{\mathrm{a}}\right) /\left(\mathrm{P}_{\mathrm{m}}-\mathrm{P}_{\mathrm{gy}}\right)\right] \times 100 \%, \\
& \% \text { shear }=\left\{1-\left(\mathrm{P}_{\mathrm{iu}}-\mathrm{P}_{\mathrm{a}}\right) /\left[\mathrm{P}_{\mathrm{m}}+0.5\left(\mathrm{P}_{\mathrm{m}}-\mathrm{P}_{\mathrm{gy}}\right)\right]\right\} \times 100 \%, \\
& \% \text { shear }=\left\{1-\sqrt{ }\left[\mathrm{P}_{\mathrm{gy}} / \mathrm{P}_{\mathrm{m}}\right)+2\right] / 3 \times\left[\sqrt{ } \mathrm{P}_{\mathrm{iu}} / \mathrm{P}_{\mathrm{m}}-\sqrt{ } \mathrm{P}_{\mathrm{a}} / \mathrm{P}_{\mathrm{m}}\right\} \times 100 \%,
\end{aligned}
$$

where $\mathrm{P}_{\mathrm{gy}}, \mathrm{P}_{\mathrm{m}}, \mathrm{P}_{\mathrm{iu}}$ and $\mathrm{P}_{\mathrm{a}}$ are characteristic points on the load-time diagram which will be described later.

This portion of the paper discusses the correlation between visually measured shear fracture percentages and those estimated from the load-time traces of the instrumented $8-\mathrm{mm}$ and $2-\mathrm{mm}$ design strikers. A typical load-time trace from an instrumented CVN test is presented in Fig. 13. The load at the point of general 
ORNL-DWG 94-13992

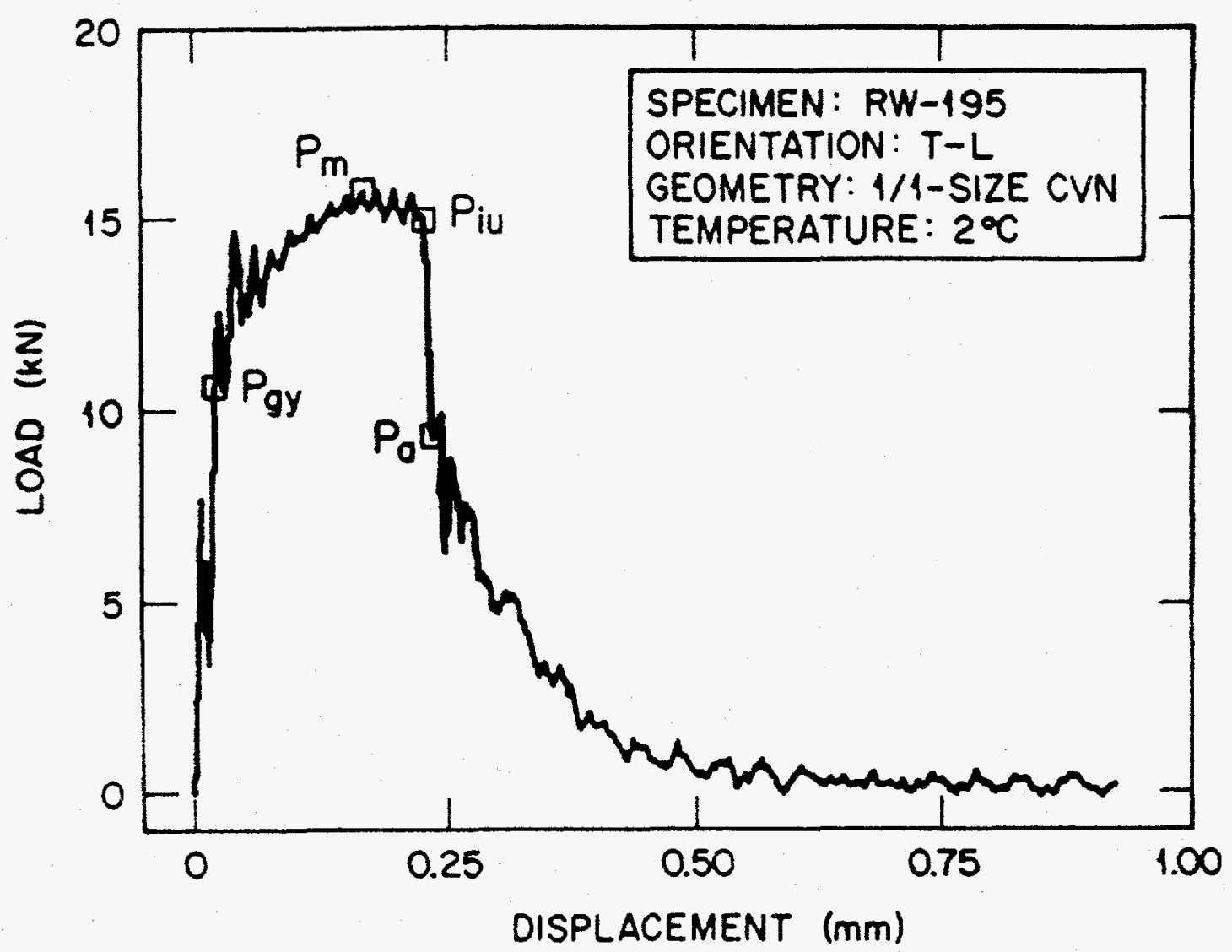

FIG. 13. Load versus time record showing the definitions of the various load points used in various models to estimate the percent shear fracture. 
yield, $\mathbf{P}_{\mathrm{g}}$ is a characteristic value of the onset of plastic deformation and it was determined as the load at the intersection of the linear rising portion of the load-time trace and the fitted curve through the oscillations of the load-time trace following the onset of the plastic strain part to maximum load. The maximum load, $\mathbf{P}_{\mathbf{m}}$, is the largest load in the course of the load-time trace and was determined as the maximum value on the fitted curve through the oscillations of the load-time trace in the area of the maximum load. The load at the initiation of unstable crack propagation, $P_{\text {iu }}$, characterizes the start point of the unstable crack propagation and was determined as the load at the beginning of the rapid drop-in-load in the load-time trace. The load at the end of unstable crack propagation, $P_{\mathrm{a}}$, characterizes the point of crack arrest and was determined as the load at the end of the drop-in-load in the load-time trace.

The load-time traces of HSST Plate 03 and the LUS weld specimens, tested by $8-\mathrm{mm}$ and $2-\mathrm{mm}$ strikers, were analyzed using Eqs. (1) through (4) to calculate the value of percent shear fracture. The calculated values were then compared with the visually measured percent shear fracture (see Figs. 14 through 17). No significant differences were observed between values of shear calculated from instrumented 8-mm or 2-mm striker traces for all four models. Thus, the same approach can be used for both striker geometries. Furthermore, each of the four models provides an overestimation of percent shear compared with the visually measured value. Of the four models (i.e., equations), the relatively simple model 1 showed closer correlation with visually measured percent shear. The more complicated model 4 showed the worst correlation. This overestimation can be explained by closer consideration of the proposed models. The main approach is based on association of the cleavage portion of the fracture with the ratio of the drop-in-load value $\left(\mathrm{P}_{\mathrm{iu}}-\mathrm{P}_{\mathrm{a}}\right)$ to the maximum load $\mathrm{P}_{\mathrm{m}}$ in model 1 , with some variations in models 2,3 , and 4 . The maximum load $\mathrm{P}_{\mathrm{m}}$ is considered the point at the beginning of crack extension. However, the ductile portion of the fracture can be formed also during flow of the material (plastic deformation), which begins at the point of general yield. Taking that into account, then, we consider an equation:

$\%$ shear $=\left[1-\left(\mathrm{P}_{\mathrm{iu}}-\mathrm{P}_{\mathrm{a}}\right) / 0.5\left(\mathrm{P}_{\mathrm{gy}}+\mathrm{P}_{\mathrm{m}}\right)\right] \times 100 \%$,

as a more reasonable formula for estimation of the percentage of shear fracture from the instrumented $C V N$ specimen test, where $0.5\left(\mathrm{P}_{\mathrm{gy}}+\mathrm{P}_{\mathrm{m}}\right)$ can be assumed to be the load at the point of material flow. Comparison of visually measured and calculated percent shear by the proposed Eq. (5) shows good correlation (see Fig. 18). In the range of small percentages of shear calculation, Eq. (5) can provide negative values which should be assumed equal to zero. Determination of percent shear fracture based on calculation from the instrumented striker provides a more objective value and can be especially worthwhile for testing of irradiated specimens or any specimens where interpretation of the fracture surfaces could be difficult. 


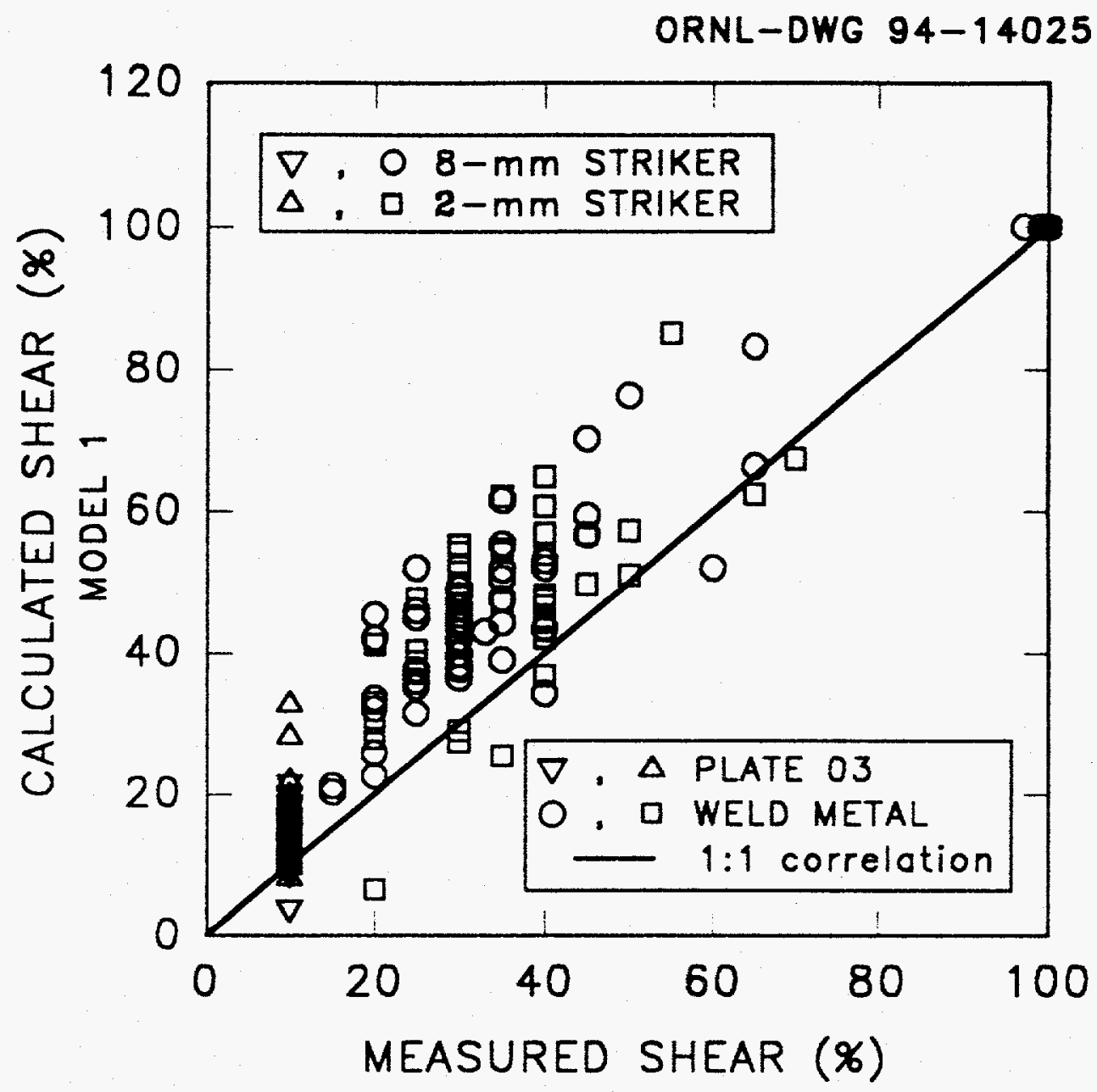

FIG. 14. Calculated shear from instrumented strikers using Model 1 (see text) versus visual measurements for A 533 grade B class 1 steel (HSST Plate 03) and a high-copper, low upper-shelf submerged-arc weld metal. 


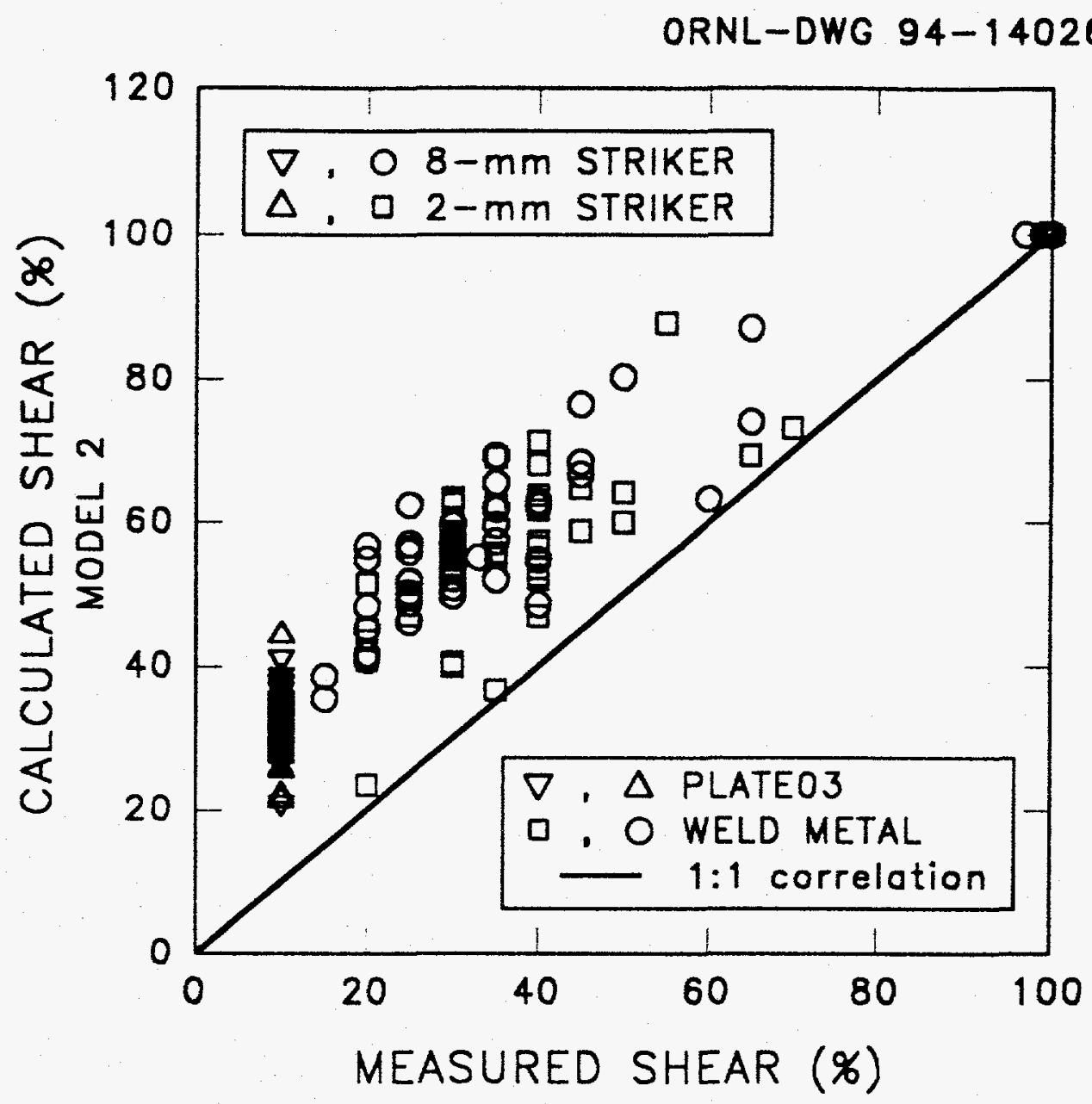

FIG. 15. Calculated shear from instrumented strikers using Model 2 (see text) versus visual measurements for A 533 grade B class 1 steel (HSST Plate 03) and a high-copper, low upper-shelf submerged-arc weld metal. 


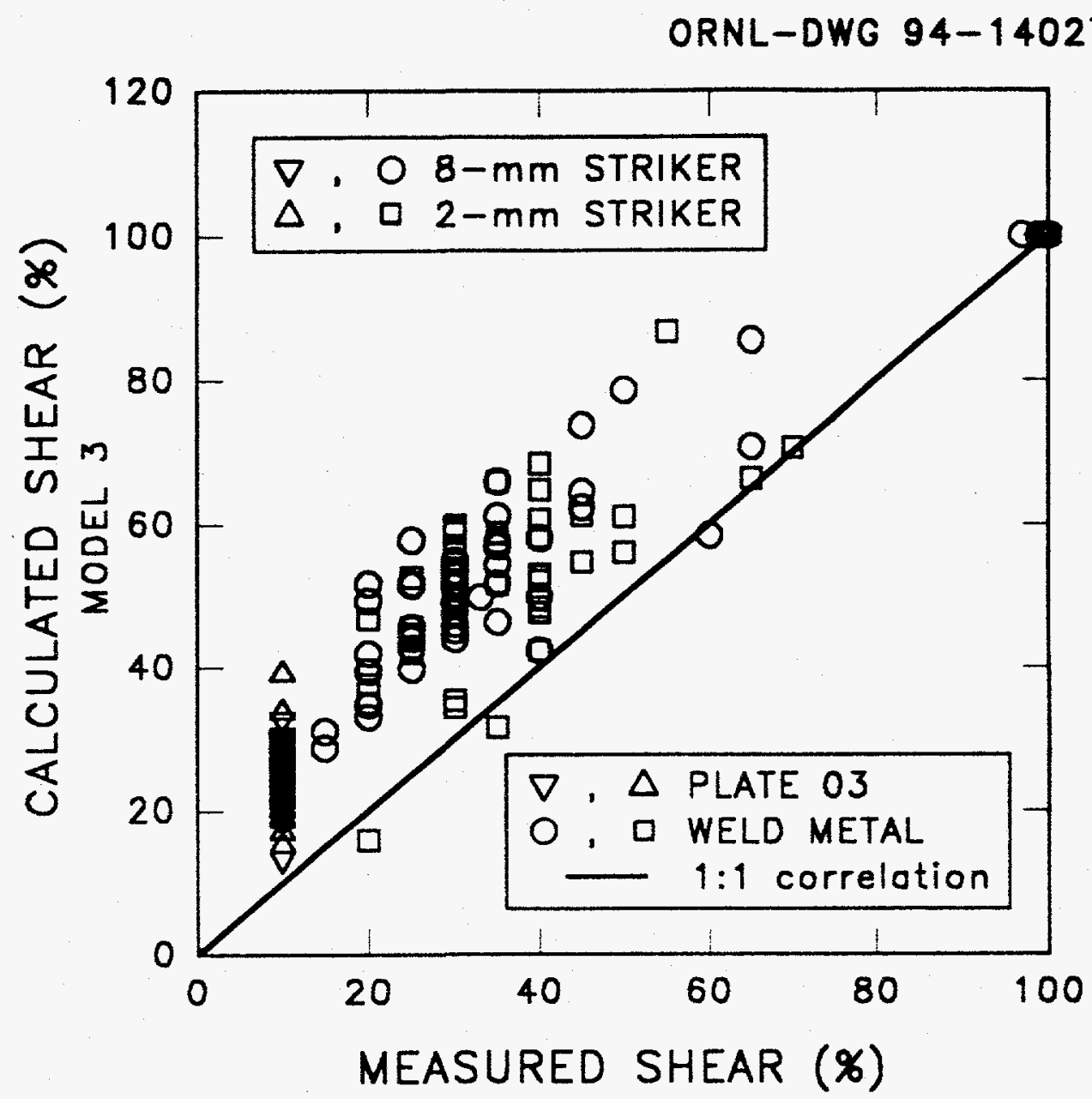

FIG. 16. Calculated shear from instrumented strikers using Model 3 (see text) versus visual measurements for A 533 grade B class 1 steel (HSST Plate 03) and a high-copper, low upper-shelf submerged-arc weld metal. 


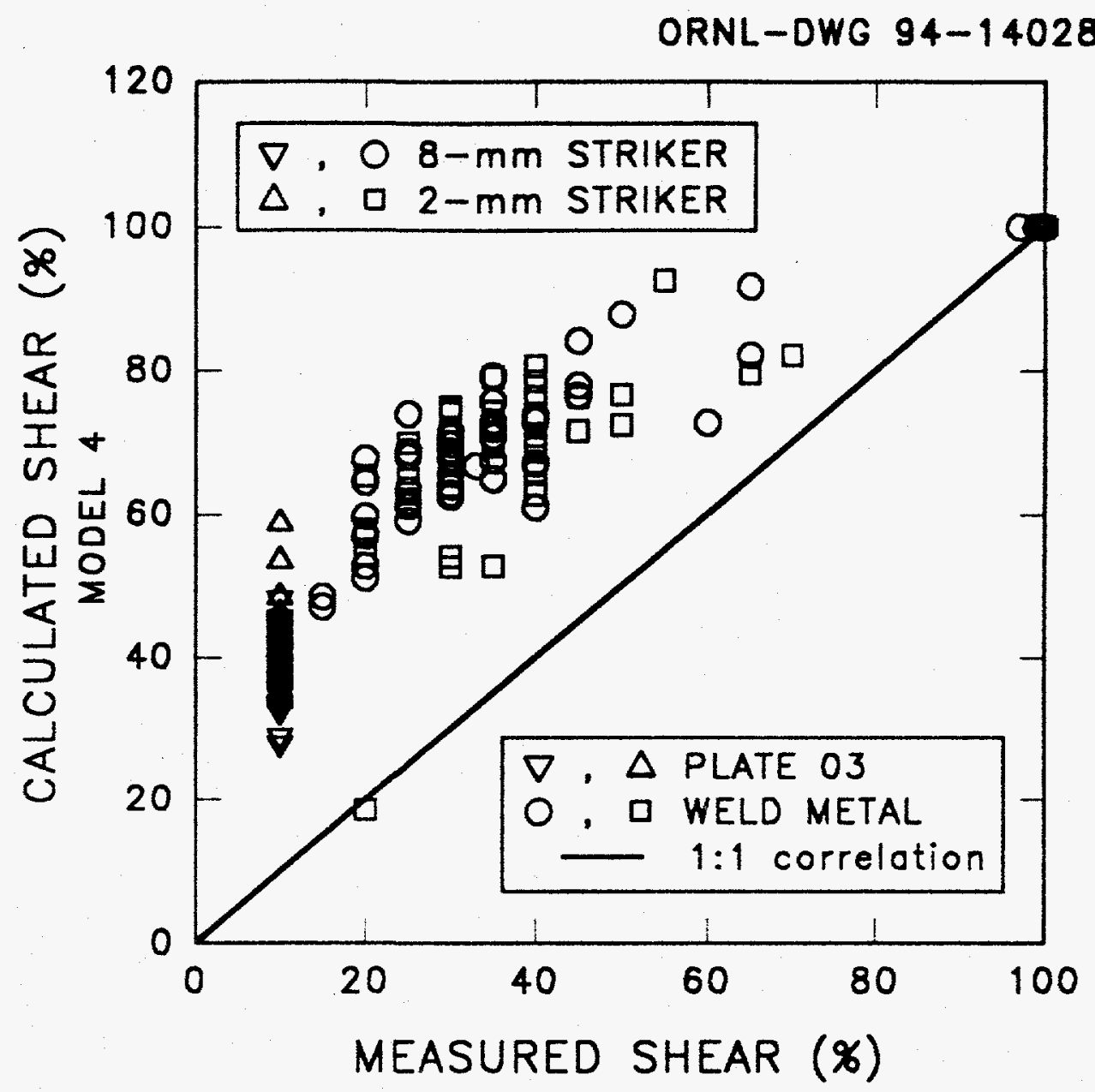

FIG. 17. Calculated shear from instrumented strikers using Model 4 (see text) versus visual measurements for A 533 grade B class 1 steel (HSST Plate 03) and a high-copper, low upper-shelf submerged-arc weld metal. 


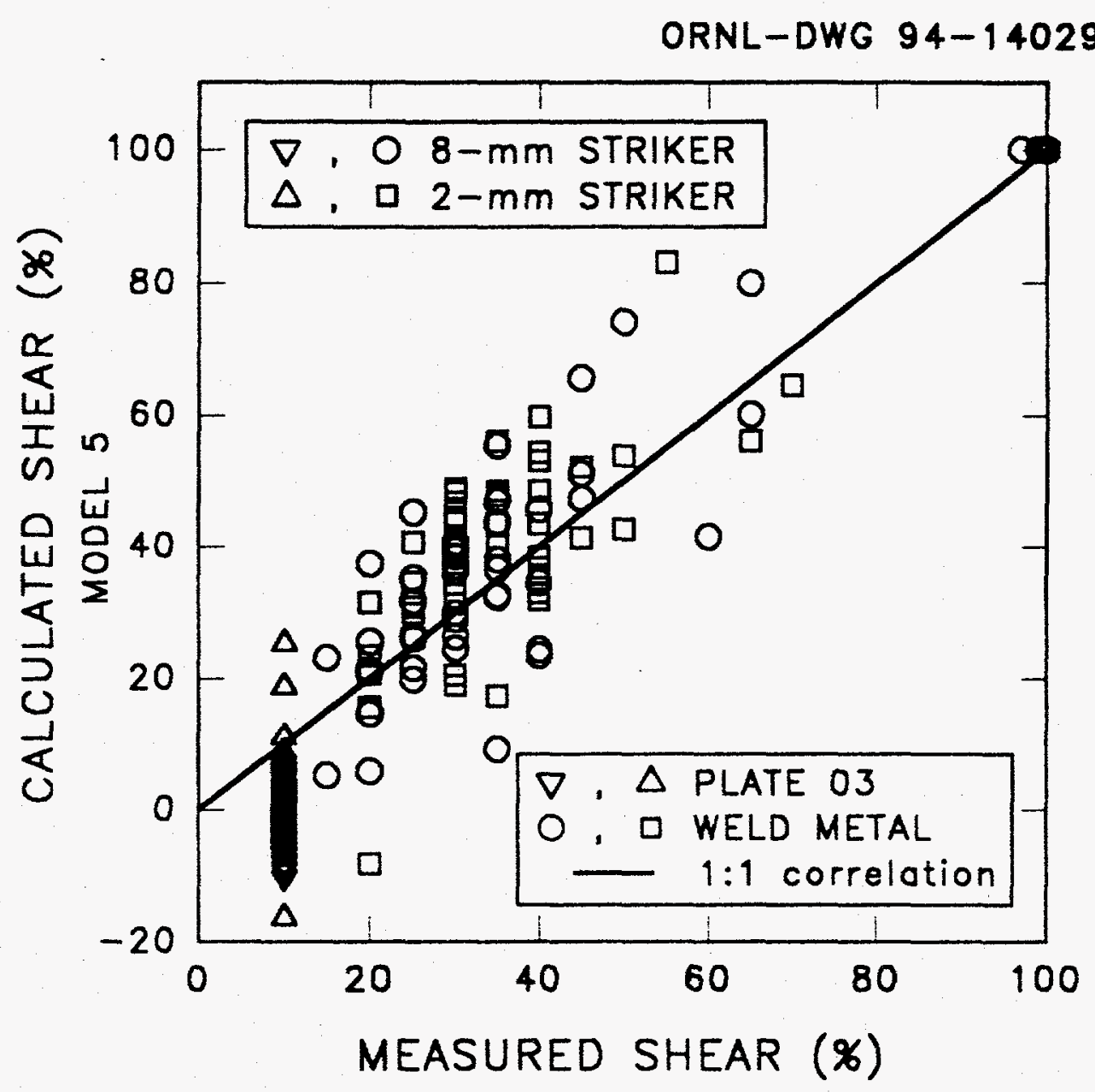

FIG. 18. Calculated shear from instrumented strikers using ORNL proposed model (see text) versus visual measurements for A 533 grade B class 1 steel (HSST Plate 03) and a high-copper, low upper-shelf submerged-arc weld metal. 


\section{CONCLUSIONS}

Five different low-alloy pressure vessel steels, a U.S. plate, a Russian forging, and two U.S. submerged-arc welds, were tested in various programs to evaluate differences in test results between the instrumented $8-\mathrm{mm}$ and $2-\mathrm{mm}$ strikers. The number of replicate tests ranged from as low as 2 to as high as 46 . Although most of the testing was performed on the same machine, comparisons were also made with results from other machines. Testing with each striker was also conducted with the high-strength $\mathbf{4 3 4 0}$ steel verification specimens supplied by NIST. Additional analyses of the test results, especially the force-time traces, remain to be performed, but the following observations and conclusions can be stated:

1. The results of tests of the NIST verification specimens with 2-mm and 8-mm strikers show close agreement at the "low" (16-J) and "high" ( $102-\mathrm{J})$ energy levels, but the 2 -mm striker measured about $11 \%$ lower energy at the "super high" $(-217-J)$ level.

2. For energy measurements, the overall results for the low-alloy steels showed good agreement, within one standard deviation, up to about $175 \mathrm{~J}$.

3. For lateral expansion measurements, the overall results for the low-alloy steels showed somewhat greater values, up to about $8 \%$, for the 2 -mm striker tests.

4. The load-time record from the instrumented 8-mm striker sometimes shows an effect of loading not associated with fracture of the specimen.

5. The instrumented striker load-time record can be used to estimate the percent shear fracture and a proposed model shows good agreement with visual measurements. In this regard, no differences were observed between the $2-\mathrm{mm}$ and 8-mm strikers.

\section{ACKNOWLEDGMENTS}

The authors acknowledge the programmatic support of the Heavy-Section Steel Irradiation Program at ORNL, managed by Bill Corwin; conduct of the Charpy impact tests by Eric Manneschmidt and John Henry at ORNL and Yuri Korolyev at Kurchatov Institute; supply of Charpy data from Prometey Institute by Dr. Vladimir Nikolayev; and preparation of the technical manuscript by Julia Bishop.

\section{REFERENCES}

[1] Standard Method for Notched Bar Impact Testing of Metallic Materials. ASTM Standard E-23, Annual Book of ASTM Standards, Vol. 03.01, American Society for Testing and Materials, Philadelphia, 1994. 
[2] International Standard ISO 148, Steel - Charpy Impact Test (V-Notch), International Organization for Standardization, Switzerland, 1983.

[3] O. L. Towers, "Effects of Striker Geometry on Charpy Results," Metal Construction, 15(11), 682-686 (1983).

[4] T. Naniwa, M. Shibaike, M. Tanaki, H. Tani, K. Shiota, N. Hanawa, and T. Shiraishi, "Effects of the Striking Edge Radius on the Charpy Impact Test," Charpy Impact Test: Factors and Variables, ASTM STP 1072, John M. Holt, Ed., American Society for Testing and Materials, Philadelphia, 1990.

[5] G. Revise, "Influence of Dimensional Parameter of an Impact Test Machine on the Results of a Test," Charpy Impact Test: Factors and Variables, ASTM STP 1072, John M. Holt, Ed., American Society for Testing and Materials, Philadelphia, 1990.

[6] D. A. Canonico, W. J. Stelzman, R. G. Berggren, and R. K. Nanstad, "Use of Instrumented Charpy Tests to Determine Onset of Upper-Shelf Energy," Weld. J. (Miami) 60(5), 85-91 (May 1981).

[7] R. K. Nanstad and R. G. Berggren, Irradiation Effects on Charpy Impact and Tensile Properties of Low Upper-Shelf Welds, HSSI Series 2 and 3, NUREG/CR-5696 (ORNL/TM-11804), August 1991.

[8] ESIS Instrumented Charpy-V Standard, Proposed Standard Method for the Instrumented Charpy-V Impact Test on Metallic Materials, Draft 10, European Structural Integrity Society, January 14, 1994. 